\title{
Neural Changes Associated with Treatment Outcome in Children with Externalizing Problems
}

By

Steven Woltering

A thesis submitted in conformity with the requirements

for the degree of Doctor of Philosophy

Department of Human Development and Applied Psychology

Ontario Institute for Studies in Education

University of Toronto

(C) Copyright by Steven Woltering 2012 


\title{
Neural Changes Associated with Treatment Outcome in Children with Externalizing Problems
}

\author{
Doctor of Philosophy 2012 \\ Steven Woltering \\ Department of Human Development and Applied Psychology \\ University of Toronto
}

\begin{abstract}
The current thesis directly investigated whether changes in the neural correlates of self-regulation (SR) are associated with the effectiveness of treatment for children's externalizing problems. In order to test this, seventy-one children 8-12 years of age with clinical levels of externalizing behaviour and their parents completed a 12-week cognitive behavioural therapy program (12 sessions) with a parent management training component that was aimed at improving SR. Electroencephalogram (EEG) correlates of SR were evaluated before and after treatment with a go/no-go task requiring inhibitory control on the children. Results showed that event-related potential (ERP) correlates of SR, such as the frontal N2 and frontal P3 event-related potential magnitudes, differed between the clinical sample and a matched comparison group before treatment: the clinical sample had larger N2 magnitudes and smaller frontal P3 magnitudes. Children who showed improvement (45\%) with treatment demonstrated a decrease in the magnitude of the N2 in comparison with children who did not improve. For improvers only, source analysis during the time period of the N2 modeled activation decreases in dorsomedial and ventromedial prefrontal cortex as well as the anterior medial temporal lobe. A decrease in N2 magnitudes and corresponding reductions in source activation,
\end{abstract}


in children who improved with treatment, might reflect improved efficiency in the neural mechanisms of SR. These findings may be important steps toward a better identification of neural markers of SR and a better understanding of the mechanisms of treatment efficacy. 


\section{ACKNOWLEDGEMENTS}

Obtaining the $\mathrm{PhD}$ has been a journey along which I have gained more than just knowledge and skills. I feel blessed with the people I met throughout. It would be impossible, and tedious, to list them all, but I do want to name those who have had a large impact on the completion of my dissertation.

I want to start by thanking my supervisor, Marc Lewis, for his unequivocal trust, relentless intellectual stimulation, and kindhearted generosity, these past years. From the first day, he has courageously involved me in all facets of running a research lab, were it grant writing, ethics applications, training sessions, important hiring and financial decisions. Because of his openness, I have learned to function quite independently, and confidently, in a team. I have also gained a deep (yet painfully acquired) appreciation for the art of writing, but this is something I will now gratefully carry with me in my future career. Sometimes, working with Marc felt like trying to contain a whirlwind, as he always challenged the status quo, intellectually and organizationally, but it taught me to think on my feet, and to anticipate the unexpected.

Connie Lamm has also been a mentor, as well as a good friend, to me from the beginning until the last day leading up to the defense. She has taught me much of the ins and outs of the EEG methodology, and how to care for a lab in general. In doing so, she became a shining example in the field for me. I am also grateful for Rebecca Todd, Kathryn Hum, and Zhongxu Liu, who played an important role in keeping my $\mathrm{PhD}$ on track by providing me with invaluable feedback on manuscripts, strategic advice, and always an understanding ear to complain to.

The dissertation is a product of the work of many people, and it would have been 
impossible to manage all the data collection, processing, and organization by myself. Project- and lab coordinators such as Arland O'Hara and Xiaowen Xu have been amazing, as have my fellow grad students (Nick, Monika!), volunteers, research assistants, project students, and the people I collaborated with from the treatment agencies. I also need to mention the departmental staff, which has always been kind and supportive. Special thanks go to Diane and Lisa from the North wing for their warm and welcoming, smiles every morning, and their patience in providing me with the necessary administrative updates and other miscellaneous instructions (not limited to how to water plants...). During my time at OISE, the lab and the department, has become like a family to me, and I have always gone there with pleasure.

I would also like to thank my thesis defense committee, who provided me with valuable comments before, during, and after, the defense. I look forward to continue working with Dr. Rosemary Tannock, and the wonderful project and group we currently have. Many thanks to Karizma, and the rest of the gang, for their confidence in me, keeping everything running during my defense-crunch, feedback on practice talks, and a great "surprise" celebration!

Last, this entire journey wasn't possible without special friends and family. Particularly helpful in supporting me throughout my thesis project were Terry Borsook, Mahshid Azimi, Ida Moadab, and Qi Gao. But above all, the pillars underneath finishing this degree were held strong by my family. Especially my parents, who have always been understanding towards my choices in life, even if it meant I was on a different continent. I am sad to realize that my mother won't be here with me on this day. I know she'd be proud. 


\section{TABLE OF CONTENTS}

Title page

Abstract ii

Acknowledgements iii

Table of Contents vi

List of Tables viii

List of Figures viii

CHAPTER 1

Introduction 1

1.1 Overview 1

1.2 Self-regulation and its development 3

1.3 Types of self-regulation 4

1.3.1 Reactive self-regulation 5

$\begin{array}{lll}\text { 1.3.2 Deliberate self-regulation } & 6\end{array}$

1.3.3 Development of different types of self-regulation $\quad 7$

1.4 The neuroscience of self-regulation 7

1.4.1 Regulatory systems in the brain: the model of vertical integration $\quad 8$

$\begin{array}{lll}1.4 .2 & \text { Reactive self-regulation } & 9\end{array}$

$\begin{array}{ll}\text { 1.4.3 Deliberate self-regulation } & 10\end{array}$

1.5 Investigating changes in the neural correlates of self-regulation 11

$\begin{array}{ll}\text { 1.5.1 ERP markers of self-regulation } & 11\end{array}$

1.5.2 Intervention studies with a neural component 12

1.6 Present Study 13

$\begin{array}{lll}1.7 & \text { Hypotheses } & 14\end{array}$

CHAPTER 2

Method

$\begin{array}{lll}2.1 & \text { Participants } & 17\end{array}$

2.2 Intervention 20

2.3 Procedure 21

2.4 Measures and tasks $\quad 22$

2.4.1 ERP task 22

2.4.2 Questionnaires and group classification 24

$\begin{array}{lll}2.5 & \text { Processing and analysis } & 27\end{array}$ 
2.5.1 EEG Data acquisition and processing 27

2.5.2 Eye blink correction methodology 29

2.5.3. EEG data analysis 32

2.5.4 Source space analysis 32

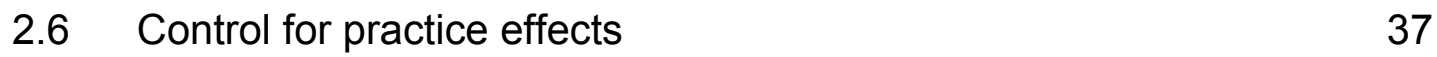

$\begin{array}{lll}2.7 & \text { Statistical analysis } & 38\end{array}$

CHAPTER 3

Results 39

3.1 Behavioural results 39

3.2 ERP results: Clinical versus Comparison group 41

3.3 ERP results: pre-versus-post-treatment 42

3.4 Source model results $\quad 47$

CHAPTER 4

Discussion $\quad 49$

4.1 Individual differences: clinical and comparison group 49

4.2 Treatment effects: ERP and behavioural results 50

4.3 Treatment effects: source analysis results 52

4.4 Neural hubs of self-regulation: the ACC 53

4.5 The role of anxiety in aggression 56

4.6 Limitations and important considerations 58

4.6.1 Assessing effects of treatment without a control group $\quad 58$

4.6.2 Validating the distinction between deliberate and reactive self-regulation 59

4.6.3 Methodological notes on source analysis 60

4.6.4 Limitations in clinical diagnoses and assessments 60

4.6.5 Effects of block: the emotion induction 62

4.7 Significance, implications, and future directions 62

$\begin{array}{lll}4.8 \text { Conclusion } & 64\end{array}$

$\begin{array}{lr}\text { REFERENCES } & 65\end{array}$ 


\section{LIST OF TABLES}

Table 1. Demographic data

Table 2. Trial count information: mean and standard deviations of trial counts for each block and session

Table 3. Regions of interest for source space analysis. Brodmann areas (BA) and names of brain regions associated with the regions of interest

Table 4. Means and standard deviations for behavioral data for clinical and comparison group

Table 5. Means and Standard deviations of clinical measures

Table 6. Mean amplitudes and standard deviations in microvolts for ERP data for clinical and comparison group for block $\mathrm{A}$ and $\mathrm{C}$

\section{LIST OF FIGURES}

Figure 1. Self report rating scale with mean scores (and error bars) of Negative Affect for each of the blocks

Figure 2. Dorsomedial and ventromedial regions of interest

Figure 3. Dorsolateral PFC, ventrolateral PFC, and anterior medial temporal lobe regions of interest.

Figure 4. The N2 event-related potential results at pre- and post visit

Figure 5. Grand-averaged stimulus-locked correct no-go event-related potential waveforms, collapsed across block $A$ and $C$ for improvers (IMPs) at preand post-treatment at site $\mathrm{FCz}$ 


\section{CHAPTER 1}

\section{Introduction}

\subsection{Overview}

Externalizing behaviour problems pose major psychological as well as financial costs to society, families, and individuals. Approximately half of all referrals to children's mental health agencies are for externalizing behaviour problems (Patterson, Dishion, \& Chamberlain, 1993; Stouthamer-Loeber, Loeber, \& Thomas, 1992). Aggression in childhood, being a key characteristic of externalizing behaviour problems, is linked to severe psychosocial maladjustment across several domains including peer relations and academic functioning (Tremblay et al., 1992). Moreover, childhood aggression is predictive of later occupational instability, unemployment, marital problems (Caspi, 1987; Farrington, 1989; Loeber \& Dishion, 1983; Patterson, Reid, \& Dishion, 1992; Reef, Diamantopoulou, van Meurs, Verhulst, \& van der Ende, 2010), depression, risky sexual behaviour, and substance abuse (Bongers, Koot, van der Ende, \& Verhulst, 2008; Robins \& Price, 1991; Timmermans, van Lier, \& Koot, 2008; Tremblay, Pihl, Vitaro, \& Dobkin, 1994).

Treatment starting in childhood can be effective, but effect sizes are generally small to moderate and there is significant variability in outcomes, as approximately $40 \%$ of children fail to respond to treatment (Brestan \& Eyberg, 1998; Dumas, 1989; Kazdin, 2001; Lewis et al., 2008). Despite many studies, we know little about why certain 
children succeed and others fail to show improvement with treatment. A better understanding of the mechanisms of change that underpin this variability in outcomes could help improve treatment approaches for these problem behaviours (Hinshaw, 2007; Kazdin, 2007).

Recently, in the search for cognitive correlates of problem behaviours, clinical psychology has increasingly been informed by neuroscientific research investigating self-regulation (SR). Neuropsychological intervention studies with child populations, however, have been rare (for exception, see Lewis et al, 2008). Although such intervention studies are time-consuming and challenging to conduct, they are particularly valuable for understanding mechanisms of change. Instead of studying components of emotion regulation through experimental manipulation, treatment supposedly changes social behaviours that rely on those very SR capacities. Thus, changes in observed social behaviours can be inferred to reflect changes in SR, and brain activity in regions hypothesized to mediate SR can then be examined in relation to those changes.

The present study aimed to investigate the neural correlates of SR using EEG technology in search for a better understanding of why certain children improve with treatment and others do not. The first goal of the study was to establish neural markers of SR. Next, particular event-related potentials (ERPs), averaged electrophysiological recordings from the scalp, associated with SR processes, were tested to distinguish a population of 71 children with clinical levels of externalizing behaviour problems from an age- and gender-matched comparison group. If so, the second goal was to investigate 
whether those neural indices would show changes between 32 clinical children who improved with treatment and 39 children who did not. Following ERP analyses, source analyses were conducted on those ERPs sensitive to change, in order to estimate the brain regions responsible for activation differences at the scalp.

\subsection{Self-regulation and its development}

SR is an overarching term which refers to the modulation of one's own behaviour in relation to the emotional, cognitive, and social demands of a particular situation (Calkins \& Fox, 2002; Posner \& Rothbart, 2000). It therefore encompasses the concept of emotion regulation. Many researchers see self-regulatory skills, including those applied to the regulation of emotion, as based on executive functions (Zelazo \& Cunningham, 2007). These are the cognitive processes controlling thought and action, like goal setting, conflict monitoring, and inhibitory control. It is possible that differences in the cognitive mechanisms involved in SR play an important part in determining treatment outcomes in children with externalizing behaviour problems (Lewis et al, 2008).

In the development of SR, the control of emotions is typically regulated by others on others at birth: babies are highly emotional and constantly soothed by parents when they cry, and in early childhood children rely on caregivers for socialization when anger gets out of control. Such extrinsic types of emotion regulation are prominent in infancy and early childhood (Fox \& Calkins, 2003); but along a normative developmental trajectory, children will gradually develop the ability to regulate their own emotions and thoughts (Kopp, 1989). Such intrinsic SR will be the focus of this thesis. 
SR is thought to develop rapidly in childhood (Calkins \& Howse, 2004; Davidson, Amso, Anderson, \& Diamond, 2006; Kopp, 1989) and it helps individuals display emotional responses with appropriate intensity and form, at the correct time and place, modulate or inhibit inappropriate responses, and develop resiliency in response to various stressors (Troy, Mauss, \& Caston, in press). Effective SR has been associated with high levels of social competence (Eisenberg et al., 1993), lower levels of problem behaviours (Calkins \& Dedmon, 2000), and fewer negative emotions (Belsky, Friedman, \& Hsieh, 2001). For those reasons, the development of $S R$ is thought to be crucial for adaptive socialization. Ineffective SR, on the other hand, may lead to the development of externalizing and internalizing disorders (Cappadocia, Desrocher, Pepler, \& Schroeder, 2009). Children with these limitations have failed to develop the capacity to appropriately modulate their feelings of anger and anxiety and the behaviours that flow from them (e.g., Bradley, 2003; Calkins \& Howse, 2004). Despite the lack of good independent measures of SR, there has been a good deal of research with young children supporting the association between poor emotion regulation and externalizing outcomes. So have higher levels of aggression been reported in children who have problems with executive functions underlying SR, such as the ability to voluntarily shift attention and inhibit emotional impulses (Rothbart, Ahadi, \& Hershey, 1994).

\subsection{Types of Self-regulation}

A useful distinction in the literature on SR, and in particular emotion regulation, is that between a more reactive/automatic and a more deliberate or effortful type of regulation (Eisenberg \& Spinrad, 2004; Phillips, Ladouceur, \& Drevets, 2008). 


\subsubsection{Reactive self-regulation}

Reactive SR is fast and stimulus-driven, and it contains implicit evaluations of objects or events that can be aversive or rewarding. For example, a child who impulsively insults his friend at school when his pen gets borrowed, shows ineffective, or socially non-adaptive, reactive control. This behaviour is likely to be at odds with long-term goals, such as establishing reliable friendships or avoiding punishment for harming other people.

With reactive regulation, the line between what is regulation and what is emotion blurs somewhat, because processes of emotional arousal and emotional regulation can be seen as overlapping. In addition, some authors see emotion as both regulated and regulatory (Kappas, 2011). Reactive control over thoughts and emotions can be experimentally demonstrated in tasks like the lowa gambling task, in which children's more automatic, "bodily" appraisals guide decision-making processes (Bechara, Damasio, Damasio, \& Anderson, 1994). It is also elicited by attentional control paradigms, like the dot probe task, in which engagement away from (or towards) an emotional stimulus can be observed (Bar-Haim, Lamy, Pergamin, BakermansKranenburg, \& van IJzendoorn, 2007; Pourtois, Schwartz, Seghier, Lazeyras, \& Vuilleumier, 2006). This task shows, for example, that reactive regulation can rely on attentional biases of threat perception, which rapidly appraise the situation in a negative light and generate an impulsive response. These and other tasks demonstrate that our feelings, perceptions, appraisals, and actions can be regulated and influenced by 
relatively automatic processes over which we do not exert intentional or conscious control.

\subsubsection{Deliberate self-regulation}

Deliberate, or effortful, SR is slow, reflective and sensitive to context and strategy, and it comprises long-term strategies such as reappraisal (Eisenberg et al., 2004; Gross \& Thompson, 2007; Posner \& Rothbart, 2009). For example, a child who feels anxious or angry at school because of a disappointing grade may reduce this feeling by deliberate strategies such as reappraisal and planning -- thinking that other smart children also had difficulties, which may suggest that the exam was too hard. These regulatory processes minimize the unwanted state of fear or anger. Such strategies serve to lessen the duration and intensity of a negative emotional state. Thinking that one's father won't be too disappointed, or that the grade may have been a mistake, allows one to attribute the negative feeling to something outside oneself and to optimize perceived control.

Deliberate control is generally intentional and presumes executive control of attention (Bargh \& Ferguson, 2000). Reappraisal is a powerful mechanism of deliberate control and is perhaps best demonstrated in classic studies requiring subjects to alter their attributions or interpretations of the causes of their emotions (Gross, 1998; Ochsner, Bunge, Gross, \& Gabrieli, 2002; Schwarz \& Clore, 1983). Deliberate regulation can also be examined in tasks that require voluntary control of more automatic mechanisms such as suppression (Goldin, McRae, Ramel, \& Gross, 2008), and delay of gratification paradigms (Metcalfe \& Mischel, 1999). 


\subsubsection{Development of different types of self-regulation}

Whereas reactive abilities are shared with many different species and are dominant early in development, deliberate control becomes more important later in childhood and is more specific to higher primates (Braver \& Barch, 2006). Given a normative trajectory, deliberate control is thought to emerge around the age of 2-3 years (Posner \& Rothbart, 1998) and to continue to develop into childhood and adolescence (Murphey Bridget, Eisenberg, Fabes, Shepard, \& Guthrie, 1999). However, already by the end of the first year, some researchers have observed signs of deliberate control of attentional processes (Diamond, 1990; Kochanska, Murray, \& Harlan, 2000; Ruff \& Rothbart, 1996). Typically, younger children gradually move from stimulus-bound, reactive responses to more deliberate and flexible strategies aimed at temporally distant goals (Lewis, Lamm, Segalowitz, Stieben, \& Zelazo, 2006; Metcalfe \& Mischel, 1999; Zelazo \& Cunningham, 2007). Especially in late childhood, when social relationships with peers become more complex and prominent, the development of an effective level of deliberate SR becomes crucial for a child's wellbeing and social success. Though speculative, effective emotion regulation may depend on the coordination between reactive and deliberate regulation. For example, ineffective reactive regulation may be compensated for by effective deliberate regulation.

\subsection{The neuroscience of self-regulation}

Over the last decade, a lot of progress has been made in uncovering the neural correlates of SR and its different subtypes. 


\subsubsection{Regulatory systems in the brain: the model of vertical integration}

A simple heuristic for thinking about SR in the brain is the idea of vertical integration (Tucker, Derryberry, \& Luu, 2000). This implies a vertical axis running through the brainstem, diencephalon (thalamus and hypothalamus), limbic structures (amygdala, hippocampus) and striatum, and finally the cerebral cortex. Typically, the lower-level structures of the neuroaxis are phylogenetically older and more strongly connected to bodily and emotional systems than the higher-level structures. The highest-level structures, including the dorsal and lateral regions of the prefrontal cortex, support more sophisticated processes like planning, reflection, judgment, and voluntary control. These structures rely on lower systems to function properly, whereas the reverse is not necessarily true (Goldstein \& Oakley, 1985). Given this perspective, emotion regulation can be conceived as a distributed function mediated by reciprocal interactions among many systems both across and within levels of the neuroaxis (Lewis \& Todd, 2007). Thus, rather than think of emotion regulation as exclusively cortically mediated -- higher-level cognitive processes inhibiting primitive, subcortically mediated urges and emotions -- emotion regulation can take place within and between every level of the neuroaxis—cortical as well as subcortical—and these levels are in constant interaction.

Similarly, within the cortex, there is a constant interaction between dorsal and ventral systems. The distinction between a dorsal (top) and ventral (bottom) system, describing a functional organization of the cortex, is well-established (Borst, Thompson, \& Kosslyn, 2011) and has also been used to explain different styles of SR (Lewis, 
Granic, \& Lamm, 2006; Stieben et al., 2007). As mentioned, dorsal PFC systems, such as the dorsal anterior cingulate cortex (ACC), mediate the smooth and deliberate control of behaviour in a top-down, supervisory fashion. Ventral PFC systems, such as the orbitofrontal cortex (OFC), on the other hand, are more directly connected to subcortical systems and mediate a reactive type of regulation, controlling impulses in a more bottom-up fashion.

This model of integration will be helpful to keep in mind as the neural bases of the different types of SR are reviewed. I will start with an overview of the neural underpinnings of reactive and deliberate SR, and then go on to describe their development.

\subsubsection{Reactive self-regulation}

Converging evidence from EEG source localization (techniques that estimates from scalp activation where in the brain activation is coming from) as well as fMRI studies suggests that the ventral ACC, OFC, and structures in the inferior temporal lobe, such as the amygdala, are involved with a reactive type of SR (Bishop, 2007; Bush, Luu, \& Posner, 2000; Ochsner \& Gross, 2007; Phillips et al., 2008).

One reason the "paralimbic" cortical systems—-the ventral ACC and OFC — are thought to mediate reactive SR because these systems are tightly wired up to bodily systems. First, the ventral ACC is strongly linked to the adaptation to behavioral demands through the regulation of the autonomic nervous system (Critchley et al., 2003). Second, quick, emotional action tendencies like rage and fear seem to be mediated by the amygdala, hypothalamus and the periaqueductal grey in the brain stem 
(Panksepp, 2004; Sabatinelli, Bradley, Fitzsimmons, \& Lang, 2005; Thomas et al., 2001). Thus, for example, the adaptive response provided by a fearful association (e.g., mother's angry shout) would be subserved by systems such as the amygdala. Third, the amygdala is associated with rapid appraisal, perceptually tagging salient stimuli for further processing, with the aid of limbic and paralimbic regions such as the hippocampus, OFC, and ventral ACC (Amaral, Price, \& Pitkanen, 1992; Davis \& Shi, 2000).

Subcortical structures were traditionally viewed as generating the valence and intensity of emotions. However, consistent with the idea of vertical integration, recent studies show that they can also be perceived as regulatory (Padmala \& Pessoa, 2008). For example, feedback from the amygdala to visual cortex modifies perceptual pick-up (Surguladze et al., 2003), and Cunningham and colleagues (2008) showed that a rapid amygdala response sets the course for subsequent prefrontal processing. Furthermore, the release of neuromodulators by brain-stem nuclei can shift other (higher level) structures into more adaptive states (Panksepp, 2004) and highlight sensory cues before they reach the cortex (Merker, 2007).

\subsubsection{Deliberate self-regulation}

Deliberate emotion regulation, on the other hand, is most consistently associated with dorsal and lateral frontal cortical regions, including the dorsolateral prefrontal cortex (dIPFC), ventrolateral prefrontal cortex (VIPFC), and paralimbic regions like the dorsal ACC (Bishop, 2007; Bush et al., 2000; Ochsner \& Gross, 2007; Phillips, Drevets, Rauch, \& Lane, 2003; Phillips et al., 2008). The dorsal ACC, on the medial wall of each 
frontal lobe, is a key structure for selecting among competing choices, making judgements, monitoring one's performance, and learning (Frith, Friston, Liddle, \& Frackowiak, 1991; Gemba, Sasaki, \& Brooks, 1986). The dorsal ACC has strong connections to lateral prefrontal regions implicated in working memory and decision making, such as the dIPFC. This network is therefore thought to subserve deliberate SR. The VIPFC and dIPFC are both implicated in the use of complex sets of conditional rules (Bunge, 2004; Crone, Wendelken, Donohue, van Leijenhorst, \& Bunge, 2006), suggesting that these regions buy us time as needed for planning and intelligent, deliberate action. Moreover, the dIPFC and VIPFC, in particular the right VIPFC, are associated with the deliberate suppression of emotional behaviour as well as various reappraisal processes (Goldin et al., 2008; Hagemann, Levenson, \& Gross, 2006; Ochsner et al., 2002).

\subsection{Investigating changes in the neural correlates of self-regulation with children}

\subsubsection{ERP markers of self-regulation}

EEG (electroencephalography) is a relatively cheap, safe, and non-invasive way, of measuring brain activity in adult and child populations with a high temporal resolution. Studies have shown good retest reliability of ERP components (Segalowitz et al., 2010). Two frontal ERP components, the N2 and frontal P3, are consistently associated with SR. The N2, a frontocentral negativity measured $200-500$ ms post-stimulus in children, has been related to the inhibition of prepotent responses (Falkenstein, Hoormann, \& Hohnsbein, 1999; Folstein \& Van Petten, 2008). Increases in magnitude have been related to greater requirements for emotion regulation and higher levels of aggressive 
behaviour and negative affect (Ladouceur, Conway, \& Dahl, 2010; Lamm \& Lewis, 2010; Lewis, Lamm, et al., 2006). The frontal P3, a late frontal positive wave measured in the range of $250-900$ ms post-stimulus, has also been linked to inhibition (Jonkman, Lansbergen, \& Stauder, 2003; Smith, Johnstone, \& Barry, 2007) and increased amplitudes have been linked to more needs for emotion regulation (Lewis et al., 2006). Meta-analyses consistently found smaller P3 magnitudes to be linked to populations with externalizing behaviour problems, however, these findings mostly rely on oddball task paradigms (Cappadocia et al., 2009; Patrick, 2008). Research using go/no-go paradigms, however, seem to suggest a similar pattern (Fallgater et al, 2004) but more studies are required. The precise time window of components depends on many factors such as stimulus modality, task conditions, and participant age and may differ for each study (Smith, Johnstone, \& Barry, 2008).

The most consistent neural generators of the N2 and the frontal P3, in the context of SR, are estimated to be PFC regions such as the ACC and the OFC (Bekker, Kenemans, \& Verbaten, 2005; Bokura, Yamaguchi, \& Kobayashi, 2001; Mulert et al., 2004; van Veen \& Carter, 2002). As was mentioned in previous sections, these PFC regions have been reliably associated with SR, giving further credence investigating the N2 and frontal P3 with processes related to SR.

\subsubsection{Intervention studies with a neural component}

Very few studies have investigated the neural correlates of SR in relation to therapeutic intervention aimed at improving SR, especially in children with externalizing problems. Lewis and colleagues (2008), using a relatively small sample of children who 
were referred for externalizing behaviour problems, did not detect changes for the N2 component with treatment, nor were there any differences found between a clinical and comparison group. However, source analysis, looking at estimated activation patterns within hypothesized regions of the brain, did reveal a reduction in ventromedial PFC activation within the time-window of the N2 related to successful treatment. This could suggest improvements in reactive SR (Lewis et al, 2008). One explanation for the high activation with these children, who continue to have greater difficulties regulating themselves, is that they utilize larger, or more synchronized, regions of ventral PFC, resulting in overengaged and inefficient SR strategies (Casey et al., 1997; Lamm, Zelazo, \& Lewis, 2006; Rypma et al., 2006). One observation, common in other studies with this population, was the high comorbidity of internalizing problem behaviour associated with the sample. This observation was used to explain the reduction in ventral PFC activation. High ventral PFC activation has often been associated with an overengaged, rigid style of SR, often characteristic of children with internalizing problems. A reduction of this ventral PFC activation could then explain an improvement in SR processes, and consequently, a better treatment outcome.

\subsection{Present Study}

The present study is designed to investigate neural markers of SR and how they change with successful treatment in children with externalizing behaviour problems. I utilized a large clinical sample of children with externalizing behaviour problems, undergoing a treatment program, and an age- and sex-matched comparison group. Children were included in the study when their scores revealed clinical levels of 
externalizing behaviour problems. Children were tested before and after treatment. The study was capitalizing on the availability of a sample from a community-based treatment center, who were receiving treatment as typically provided. For this reason there was no randomization or control group. Children are compared based on their response to treatment. The treatment consisted of Cognitive Behavioural Therapy (CBT) and Parent Management Training (PMT) and treatment success was assessed by various parent and clinician reports. Children performed a go/no-go task designed to elicit the selfregulatory process of inhibitory control while their EEG was being recorded.

Neural correlates of inhibitory control were investigated by examining ERPs and estimated activity in regions of interest (ROIs) derived from source localization. ERP components, especially the N2 and frontal P3, occurring after the nogo-stimulus, have been related to inhibition and attentional control (Falkenstein et al., 1999).

\subsection{Hypotheses}

The present study had two aims:

1) To confirm the extent to which the N2 and frontal P3 ERPs could be neural markers of SR. Differences between the clinical and comparison group were expected in those measures, specifically:

a) N2 magnitude measures to be larger for the clinical group compared to the comparison group.

b) frontal P3 magnitude measures to be smaller for the clinical group compared to the comparison group. 
In addition, perceptual components, such as the N1 and P2, will also be investigated, although no specific hypotheses were devised with respect to these components.

2) To investigate the main research question of the present study: if these ERP measures distinguish between clinically diagnosed and comparison children, would these measures also change with successful treatment aimed at improving children's SR ability? Specifically, it was expected that

a) N2 magnitudes decrease in children who improve with treatment compared to children who do not show significant improvement.

b) frontal P3 magnitudes increase in children who improve with treatment compared to children who do not show significant improvement with treatment.

Both results would indicate shifts in neural activity in the direction of the comparison group (an estimate of the age-based norm). Furthermore, changes were investigated in the source activations of those ERP components. Converging evidence points to a source or generator in medial prefrontal regions such as the ACC (Bekker et al., 2005). In addition, lateral PFC regions were investigated, as reflective of deliberate control, and activity in the anterior temporal lobe (e.g., close to the amygdale) was examined as being representative of reactive SR. In keeping with previous work showing decreases in ventromedial PFC associated with reactive regulation (e.g., Lewis et al., 2008), activation in source regions was expected to 
c) decrease with treatment in the ventromedial PFC as well as the anterior temporal lobe; regions involved in reactive regulation. Also based on our previous findings, no activation changes were expected in the dorsal ACC.

d) show no change with successful treatment in areas such as the vIPFC and dIPFC, in keeping with previous results. 


\section{CHAPTER 2}

Methods

\subsection{Participants}

EEG data were collected from 139 children (107 boys, $77 \%$ ), aged 8-12, with externalizing behaviour problems, over a span of 5 years (2005-2010). Children were recruited in collaboration with two treatment agencies. Participants were referred to these agencies by mental health professionals, teachers, and/or parents. Inclusion criteria for the study consisted of scores within the clinical or borderline-clinical range on the externalizing subscale of the Child Behavior Checklist (CBCL; Achenbach, 1991). Children were excluded if they had significant developmental delays.

Seventy-one clinical children (51 boys, $72 \%$ ) with an average age of 9.5 (sd= 1.2) had usable data from both pre- and post-treatment sessions. Sixty-eight children were excluded from the study because they were unable to attend the post-treatment session ( $n=61)$, or had no useable data for essential data points $(n=7)$ due to outliers or missing data. The most common reason for nonattendance was families reporting being unable to commit to the treatment and/or study appointment. Nine or more sessions would have to be attended in order for participants to be counted as having completed treatment. Of the remaining 72 children, one child's data was removed from the analysis due to insufficient trials.

No significant differences were found for children who were excluded from the study on either the externalizing or internalizing scale of the $\mathrm{CBCL}$, age, behavioural 
measures, or event-related potential (ERP) values, as determined by independent ttests. As well, no differences were found for ethnicity, family income, or parental level of education as determined by chi-square analyses. A high comorbidity between externalizing behaviour problems and ADHD, as reported by parents, was observed in this sample (15 children, $21 \%$ ). Results of the study were not different when this subsample was excluded. The sample, similarly to Lewis, et al. (2008), showed clinical levels of internalizing problems as well as externalizing problems.

A comparison group of 24 non-clinical children, matched for age $(m=9.7, s d=$ 1.5 ) and sex (17 boys, $71 \%$ ) was recruited through newspaper ads. Children had to score below the borderline-clinical cutoff on both the internalizing and externalizing scales of the CBCL to be included as a comparison group participant. Table 1 shows information regarding the sample's demographics. 
Table 1: Demographic Data

\begin{tabular}{|c|c|c|}
\hline Family Characteristics & $(n=71)$ & $(n=24)$ \\
\hline & Clinical Group & Healthy comparison \\
\hline \multicolumn{3}{|l|}{ Living arrangement } \\
\hline Both parents & $27(38.0 \%)$ & $13(54.2 \%)$ \\
\hline Adopted & $5(7.0 \%)$ & -- \\
\hline With step-parent & $10(14.1 \%)$ & -- \\
\hline Mother only & $23(32.4 \%)$ & $11(45.8 \%)$ \\
\hline Other & $6(8.4 \%)$ & -- \\
\hline \multicolumn{3}{|l|}{ Ethnicity } \\
\hline European & $53(74.6 \%)$ & $12(50 \%)$ \\
\hline African/Caribbean - Canadian & $11(15.5 \%)$ & $3(12.5 \%)$ \\
\hline Asian-Canadian & -- & $4(16.7 \%)$ \\
\hline Other & $6(8.4 \%)$ & $5(20.8 \%)$ \\
\hline \multicolumn{3}{|c|}{ Mother's education (highest level completed) } \\
\hline Grade 8 or less & $1(1.4 \%)$ & -- \\
\hline Did not graduate high school & $8(11.3 \%)$ & $2(8.3 \%)$ \\
\hline High school & $12(16.9 \%)$ & $4(16.7 \%)$ \\
\hline Community college & $32(45.1 \%)$ & $6(25 \%)$ \\
\hline University & $9(12.7 \%)$ & $9(37.5 \%)$ \\
\hline Postgraduate/prof. & $6(8.5 \%)$ & $2(8.3 \%)$ \\
\hline Other/unknown & $2(2.8 \%)$ & $1(4.2 \%)$ \\
\hline \multicolumn{3}{|c|}{ Father's education (highest level completed) } \\
\hline Grade 8 or less & $2(2.8 \%)$ & -- \\
\hline Did not graduate high school & $9(12.7 \%)$ & $2(8.3 \%)$ \\
\hline High school & $16(22.5 \%)$ & $4(16.7 \%)$ \\
\hline Community college & $16(22.5 \%)$ & $4(16.7 \%)$ \\
\hline University & $7(9.9 \%)$ & $3(12.5 \%)$ \\
\hline Postgraduate/prof. & $2(2.8 \%)$ & $6(25 \%)$ \\
\hline Other/unknown & $1(1.4 \%)$ & $1(4.2 \%)$ \\
\hline \multicolumn{3}{|l|}{ Family income (CND\$) } \\
\hline $0-29,999$ & $17(23.8 \%)$ & $5(20.8 \%)$ \\
\hline $30,000-59,999$ & $14(19.7 \%)$ & $8(33.3 \%)$ \\
\hline 60,000 or above & $35(49.3 \%)$ & $11(45.8 \%)$ \\
\hline
\end{tabular}


For practical and ethical reasons it was not feasible to control children's medication use. Instead, I controlled for these effects statistically. Medication status was recorded when participants visited the lab. I distinguished between stimulants $(n=18$, $25 \%)$, antidepressants $(n=0)$, tranquilizers $(n=0)$, antipsychotics $(n=0)$, anticonvulsants $(n=1,1 \%)$, other $(n=13 \%)$, and no medication $(n=43,61 \%)$. 'Other' medication comprised non-psychotropic - over the counter - medication and was grouped with no medication for the subsequent analysis. No participants in the comparison group were on medication.

Analysis showed that the children on stimulant medication were not different from those without in their externalizing behaviour at pre-treatment as determined by t-tests. Furthermore, no differences were found between improvers and nonimprovers in medication status as determined by Chi-square analysis. Twelve children reported changes in medication use during the treatment, half of whom $(n=6)$ started medication during the treatment, whereas the others $(n=6)$ went off medication during this period. The exact time when they switched medication use during this period is unknown. Redoing analyses, while excluding participants who had changed their medication use, did not change any of the major findings in this study.

\subsection{Intervention}

An evidence-based treatment program called SNAP ${ }^{\mathrm{TM}}$ (Stop Now and Plan; Augimeri, Farrington, Koegl, \& Day, 2007) was delivered to children (CBT: cognitive behavioural therapy) and parents (PMT: parent management training). The SNAP ${ }^{\mathrm{TM}}$ 
program underwent two evaluations demonstrating positive treatment outcomes with effects lasting for at least 6- and 12-month follow-up periods (Augimeri et al., 2007; Hrynkiw-Augimeri, Pepler, \& Goldberg, 1996). Weekly three-hour group therapy sessions were held separately for the children and their parents at the community agencies for 14 weeks. CBT targets effective regulation of emotion and impulses through well-documented strategies such as cognitive restructuring, problem solving, role-playing, social and token reinforcements, and generalization activities (Barkley, 2000; Bloomquist \& Schnell, 2002). PMT promotes positive parenting practices such as skill encouragement, problem solving and monitoring, as well as the replacement of coercive or lax discipline strategies with mild sanctions targeting misbehaviour (Forehand, 1986; Forgatch \& Degarmo, 1999; Martinez \& Forgatch, 2001). Therapists were either social workers, child-care workers, M.A.- or Ph.D.- level clinical psychology students. Therapists were trained in the PMT and CBT protocols and regularly supervised to ensure fidelity to the treatment model.

\subsection{Procedure}

Behavioural and EEG data were collected both 2 weeks before and then 2 weeks after the 14-week treatment sessions. Children were accompanied to the lab by a parent. Following a brief introduction to the testing environment, parental consent and child assent were obtained. Parents were seated in an adjacent room and asked to complete the $\mathrm{CBCL}$, while the children were doing executive function tasks on a computer. The results of these tasks are not included in the present thesis. Next, children were informed that they could win a big prize for playing the EEG "computer 
game" and were shown two toy bins. One of the bins contained small, undesirable toys such as small plastic cars. A second, "big prize" bin contained a wide selection of more desirable, age-appropriate toys such as action figures, stuffed animals, games, and $\$ 10$ gift certificates from a local music/computer game store. As part of a mood manipulation, the children were informed that successful performance (accumulation of points) in the game would allow them to pick a prize from the big prize bin, but poor performance would limit their choice to the less desirable bin.

Children were seated in front of a computer monitor. The electrode sensor net was applied with the distance and alignment to the monitor controlled by the use of a chin rest. Children were instructed to make responses during the game by clicking a button on the response pad with the index finger of their dominant hand. Data acquisition took place in a cool and dry environment and was started after impedances for all EEG channels were reduced to below $50 \mathrm{k} \Omega$, which is acceptable with high inputimpedance amplifiers (Ferree, Luu, Russell, \& Tucker, 2001; Kappenman \& Luck, 2010).

\subsection{Measures and tasks}

\subsubsection{ERP task}

An adapted version of a previously developed go/no-go task was used for the present study (Stieben et al., 2007). The task was presented using E-Prime software (Psychological Software Tools, Pittsburgh, PA). Participants were required to press a button as fast as possible whenever a letter appeared on the screen (the go condition) 
and withhold responding whenever a letter was repeated a second time in succession (the no-go condition).

In order to provide the same level of challenge for all participants at all ages, and to obtain a sufficient number of correct no-go trials for ERP averaging, a dynamic adjustment of the stimulus time was used in the task. The no-go error-rate for the task was maintained at $50 \% \pm 10 \%$ by dynamically adjusting the stimulus duration. Stimulus duration was increased with each erroneous response made on no-go trials. Stimulus duration was decreased following correct no-go trials, but only when the no-go trial followed a correct go trial. This constraint was incorporated to prevent stimulus time adjustments due to chronic non-responding (its effects will be captured by the accuracy data: nogo trials that were not preceded by a correct go will not be counted). For each block, accumulated points were displayed approximately every 20 trials in the centre of the computer screen.

Points were added for correct no-go responses and deducted for response errors on both go and no-go trials. Error feedback was provided by a red bar in the middle of the screen following incorrect responses, omitted responses, and late responses. Since perseverative responding can lead to high accuracy on go trials and low accuracy on no-go trials, and since chronic non-responding can lead to the reverse pattern, accuracy scores as averaged across both trials types are reported in this study.

Children were presented with a practice block followed by three blocks of trials in a fixed order (blocks $\mathrm{A}, \mathrm{B}$, and $\mathrm{C}$ ). In blocks $\mathrm{A}$ and $\mathrm{C}$ children gained points quite steadily. These blocks were structurally identical, each consisting of 200 trials, including 66 no-go trials, in pseudorandom sequence. In block B, children immediately began 
losing all (or almost all) points due to a change in the point-adjustment algorithm. The loss of points was intended to induce negative emotion, such as anxiety and/or

frustration. To limit the intensity and duration of children's distress, block B consisted of only 150 trials, including 40 no-go trials. Children were reminded at the beginning of the task, and at the onset of each block, that a high number of points were required to win the "big prize". At the end of the task, all children were told that they would receive the big prize. Finally, self-report rating scales were administered to determine how the child felt during each of the blocks. The last visit had a debriefing for the parents and the child, explaining the emotion induction.

\subsubsection{Questionnaires and group classification}

Child and Adolescent Functional Assessment Scale (CAFAS): To assess improvement status, the CAFAS (Augimeri et al., 2007), a clinician's measure of child problem behaviours, was used. To rate the child, the clinician collects information from multiple informants in different settings, including the child's parents, teachers, and other significant adults (e.g., grandparent, school counselor). The reliability and validity of the instrument have been well established (Hodges \& Gust, 1995; Hodges \& Wong, 1996) and it is particularly sensitive to clinical change over time (Hodges, 1999; Hodges, Wong, \& Latessa, 1998; Hodges \& Wong, 1996). For assessing improvement status, I focused on four CAFAS scales: school, home, community, and behaviour toward others (Hodges \& Wong, 1996).

Child Behavior Check List (CBCL): The CBCL, used to determine inclusion 
criteria, is a highly reliable parent report yielding standardized T-scores for scales such as internalizing and externalizing behaviour problems. Both CAFAS and CBCL measures were administered before and after treatment.

Group classification: In terms of a group classification for improvers and nonimprovers, I focused on four CAFAS scales: school, home, community, and behaviour toward others (Hodges Wong, 1996, Hodges Wong, Latessa 1998; Hodges, 1999). A decrease of 20 points or more is considered clinically significant improvement (Hodges \& Wong Latessa, 1998). On the basis of these measures, 32 children were classified as improvers and 39 children were classified as nonimprovers. If no data were available from the CAFAS, the CBCL was used, where a drop in T-score of 5 or more on the externalizing scale was used to signify clinical improvement. This safeguard was only required for one participant. I used the CAFAS as the primary yardstick of improvement because it combined information from multiple informants, not just parents.

Emotion Scales: A self-report emotion-induction check was administered directly after the go/no-go task was completed. Children were asked to rate, on a 10-point Likert scale, the intensity of each of five different emotions (upset, mad, nervous, satisfied, and excited) for each of the blocks. Previous blocks were referred to by their sequence of occurrence (first, middle, last). Because they did not differ statistically for the sample as a whole, the three negative emotions were averaged and analyzed as a global measure of experienced negative affect (see Figure 1). 
A repeated-measures ANOVA shows a quadratic main effect of block, $F(2,34)=$ $9.09, p=.001$, partial $\eta 2=.35$. Planned contrasts revealed that Block $B$ was perceived as significantly more negative than block $A$ or $C(p<.01)$. No differences were found between block $A$ and $C(p=.34)$. 


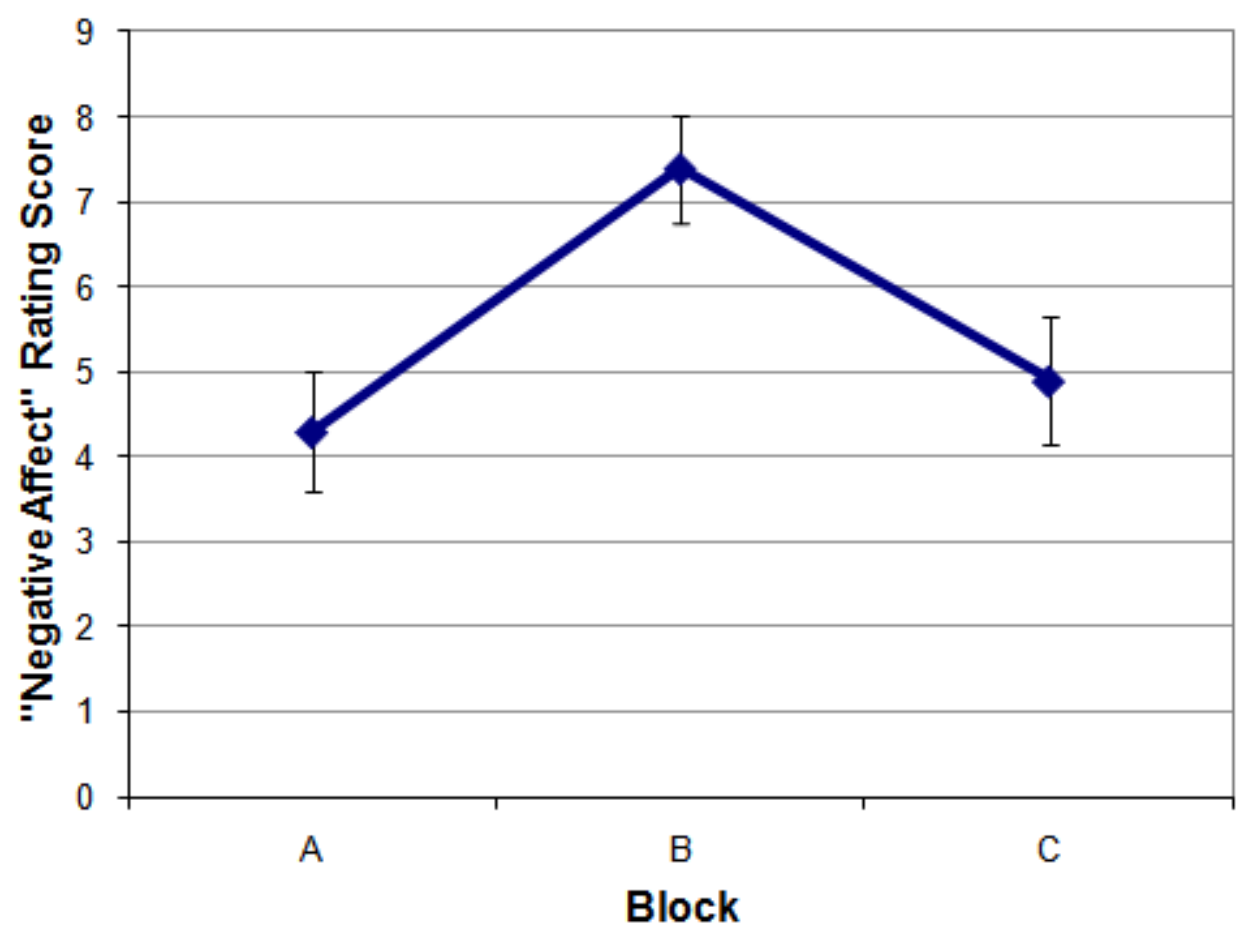

Figure 1. Self report rating scale showing mean scores (and error bars) for Negative Affect (note: 10 point max) for each of the blocks.

\subsection{Processing and Analysis}

\subsubsection{EEG Data acquisition and processing}

Data were collected using a $.01-1000 \mathrm{~Hz}$ hardware filter and a sampling rate of $250 \mathrm{~Hz}$, and were filtered off-line using a 1-30 Hz finite impulse response (FIR) bandpass. Correct no-go data were segmented into epochs from $400 \mathrm{~ms}$ before to 1000 ms after stimulus onset. Correct no-go trials that did not have a correct go trial preceding and following them were removed from analysis because they may have 
reflected attentional lapses or chronic non-responding. For the ERP analysis, regression-based eye-blink correction (Gratton, 1983) was performed to preserve trials. See the next section for a justification of this methodology. Channels were automatically marked bad when they exceeded a transition threshold of $130 \mu \mathrm{v}$ over the entire segment (max-min). Remaining eye blinks were detected when the vertical eyechannels exceeded a threshold of $135 \mu \mathrm{v}$ (max-min) within a $160 \mathrm{~ms}$ (moving) timewindow within each trial after running a $20 \mathrm{~ms}$ moving-average smoothing algorithm across the entire trial period. Eye movements were detected when horizontal eye channels exceeded a threshold of $75 \mu \mathrm{v}$ (max-min) over a $200 \mathrm{~ms}$ time window. Furthermore, each segment of the EEG was excluded from averaging if 20 or more channels were rejected. These settings were determined by extensive tests on a sample of the data and yielded the best artifact detection for our data. In addition, all segments were visually inspected by a trained research assistant blind to the hypotheses.

After averaging, all channels that were referenced to $\mathrm{Cz}$ during recording were re-referenced to an average reference. Data were baseline corrected for the $400 \mathrm{~ms}$ preceding the stimulus.

Data used for the source analysis were not processed using the eye correction tool, as regression-based correction methods may distort the source estimations. Furthermore, the effect of other eye correction methods on source localization has not been thoroughly tested. This resulted in a different number of trials and 11 fewer participants for the source analysis (see Table 2 for details on trial counts). 
Table 2.

Trial count information. Means (and standard deviations) of trial counts for each block and session.

\begin{tabular}{lllll} 
& \multicolumn{2}{c}{ ERP* Analysis $(n=71)$} & \multicolumn{2}{l}{ Source Analysis $(n=60)$} \\
& Pre & Post & Pre & Post \\
Block A & $25.9(6.6)$ & $29.0(8.7)$ & $22.1(7.6)$ & $25.9(9.5)$ \\
Block B & $10.4(3.3)$ & $12.1(4.2)$ & $9.0(3.8)$ & $10.6(5.1)$ \\
Block C & $27.8(6.7)$ & $28.9(9.0)$ & $24.1(8.0)$ & $25.9(10.7)$ \\
& & & & \\
* Event-related potential.
\end{tabular}

\subsubsection{Eye blink correction methodology}

One of the most pervasive problems in EEG research are eye blink artifacts, as they contaminate brain signals and may lead to a detrimental loss of trials and subjects as blink trials are mostly rejected. In our sample, I would have typically lost an average of $20 \%$ of our trials, and this would have led to the loss of $10 \%$ of our participants because the trial count would fall below acceptable levels for publication. Methods attempting to correct eye blinks are sometimes employed because 1) 'Rejection' can lead to an unrepresentative sample of trials, 2) The instruction to inhibit eye movements or blinks may pose additional cognitive constraints, impacting task performance 
(Verleger, 1991), 3) Some groups of subjects, children and psychiatric patients, have more difficulty controlling their blinking, and this makes it difficult to obtain a sufficient number of trials within a reasonable time.

The regression-based method (e.g., Gratton et al., 1983) has been the most widely used technique to correct for blinks. The method claims to remove the added distorting effects of the blink and leave the estimated activity of the brain. In doing so it attenuates all trials, blinks as well as no blinks. Its merits, therefore, are constantly under debate but have mostly been evaluated using simulated data, and not directly on ERP waveforms.

In order to directly test the distorting effect of the eye blink correction methods in our sample, a small test was conducted on a subsample. ERPs consisting of uncorrected trials containing no eye blinks were compared to eye-blink-corrected trials containing blinks as well as no blinks. In all analyses conducted, a minimum of 10 blink trials were compared to an equal number of randomly chosen trials containing no blinks. Five stimulus-locked ERP components were derived when subjects correctly inhibited on a nogo trial. Common ERP waves, such as the N1, P2, N2, and frontal P3, were manually coded by research assistants who were blind to the hypotheses.

We first assessed to what extent the Gratton method, which affects all data, distorts waveforms when there are no blinks. Using trials with no blinks, we compared trials that were uncorrected with the exact same trials that were corrected using the algorithm. The results show large and significant correlations for all components ( $r$ values ranging from .60 to .90 ), with stronger correlations for the earlier components. Second, we assessed how well the Gratton method corrected data that had blinks. In 
this comparison, corrected no-blink trials were compared to corrected blink trials within each subject. Note that in contrast to the first test, this analysis used different trials. Results show large and significant correlations for all components, with relatively stronger correlations for earlier components ( $r$-values ranging from .60 to .75). Third, we tested whether 'traditional' between-subject ERP differences could be replicated with corrected (blink and no-blink) data. Uncorrected no-blink ERP differences were found in two analyses (i.e., findings related to significant differences in gender and age groups). Patterns were compared using corrected blink trials and corrected no-blink trials. Results show that, generally, patterns remained consistent in magnitude, direction and significance. Some deviations were found, however, for the later components (like the frontal P3). It was concluded that, considering the number of trials and subjects that would have been lost due to eye blinks in our sample, and given that uncorrected blink data would otherwise be thrown out, the Gratton method seemed to correct blinks with acceptable levels of distortion, and this methodology was worth using. Caution should be taken, however, when interpreting later components, such as the frontal P3, which are more sensitive to distortions. One advantage the Gratton method has over other correction methods is that it requires less data manipulation, computation, and time. Moreover, studies comparing eye-blink (not eye movement) correction methodologies also suggest that regression-based methods are not inferior to ICA and source dipole methods (Hoffmann \& Falkenstein, 2008; Lins, Picton, Berg, \& Scherg, 1993; Wallstrom, Kass, Miller, Cohn, \& Fox, 2004). The data for this evaluation have been reported elsewhere (Woltering, Liu, Bazargani, \& Lewis, 2010). 


\subsubsection{EEG data analysis}

EEG was recorded using a 128-channel Geodesic Sensor Net and sampled at $250 \mathrm{~Hz}$, using stand-alone software (Electrical Geodesic, EGI). Standard EEG filtering and artifacting procedures were used to process the data. The N2 was scored as the largest local negative deflection with a medial-frontocentral topography (averaged across values recorded at $\mathrm{FCz}, \mathrm{Fz}$, and $\mathrm{Cz}$ ) between 200 and 500 ms post-stimulus. In addition, the N1 (50-175 ms) and P2 (150-250 ms) components were scored at similar sites as the most negative and positive local deflections within these time windows, respectively. The mean frontal activation (average across values recorded at $\mathrm{Fz}$, and $\mathrm{FCz}$ ) at $600-900 \mathrm{~ms}$ was used to measure the frontal P3, because grand averaged activation was found to be maximal in that time range. Scoring was performed by two independent coders blind to the hypotheses. Intercoder agreement was $89 \%$. For this study, only the amplitudes for blocks A and C were analyzed since Block B ERPs yielded insufficient trial counts to obtain reliable effects. Although no specific hypotheses were identified for differences between blocks $A$ and $C$, differences were explored by adding block as a factor in the analyses.

\subsubsection{Source space analysis}

Although EEG source-modeling does not permit precise anatomical localization, estimates of regions of activation allow for the testing of global hypotheses (Grave de Peralta Menendez, Murray, Michel, Martuzzi, \& Gonzalez Andino, 2004). In order to estimate cortical generators of ERP components, LAURA (local autoregressive average) constraints, with a regularization constant of $10^{-3}$, were applied to the ERP in order to calculate the inverse solution (for a review of EEG source localization 
techniques and settings, see Michel et al., 2004). Morphology-based regions of interest (ROIs) were generated within the GeoSource (EGI software) interface from a Montreal Neurological Institute probabilistic MRI template. I note the limitation of superimposing children's cortical activation data over an adult MRI, as detailed in the section on limitations, but that is the current standard because age-specific MRI head models have not yet been developed.

The defined ROls represented the ventromedial and dorsomedial PFC regions, which correspond with the ventral ACC, OFC and dorsal ACC, respectively. The anterior medial temporal lobe (aMTL), dIPFC, and vIPFC regions were also investigated. The maximal activation value for each voxel was exported for each ROI within a $150-\mathrm{ms}(250-400 \mathrm{~ms})$ time-window around the peak of the grand-average N2. Lastly, for each ROI, the mean value across all these voxels was exported for each participant at pre and post sessions. Table 3 , and figure 2 and 3 , provides more detailed information regarding the delimitations and associated brain regions corresponding to the ROls assessed in the source analysis. 
Table 3.

Regions of interest (ROIs) for source space analysis. The table presents Brodmann areas (BA) and names of brain regions associated with the ROls.

$\begin{array}{lll}\text { ROI name } & \text { Brain regions } & \text { Main BA regions } \\ \text { Ventral } & \begin{array}{l}\text { Ventromedial PFC } \\ \text { Orbitofrontal cortex }\end{array} & 25,11 \\ & \text { Subgenual ACC } & \\ \text { Dorsal } & \text { Dorsal ACC } & 24,32 \\ \text { Dorsolateral } & \text { Dorsolateral PFC } & 9,10,45,46 \\ \text { Ventrolateral } & \text { Ventrolateral PFC } & 10,47 \\ \text { Anterior Temporal } & \text { Medial uncus lobe } & 28,20,36 \\ & \text { Amygdalar Gyri } & \end{array}$

ACC, anterior cingulate cortex; PFC, prefrontal cortex. 


\section{Dorsal ROI}

Sagittal
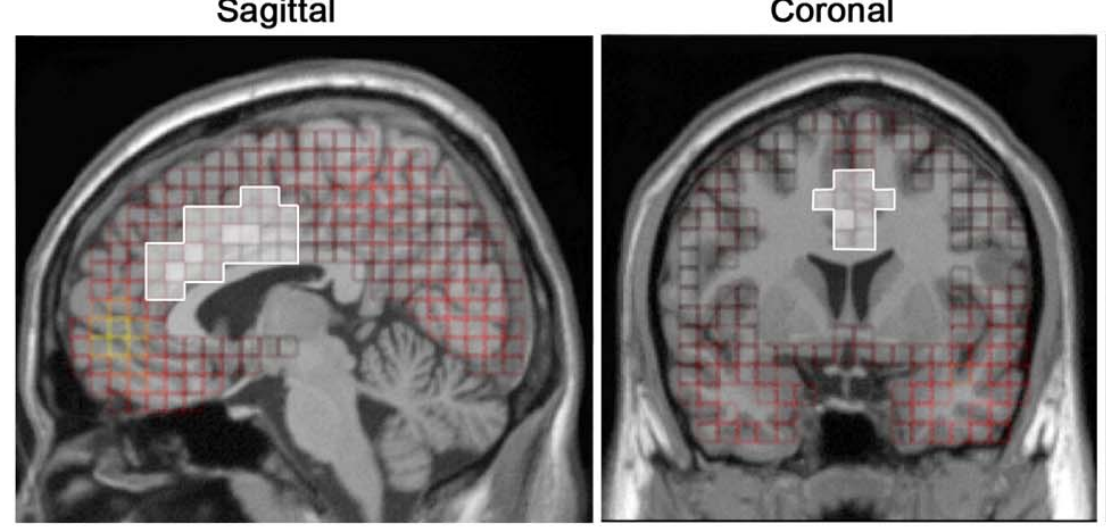

Ventral ROI

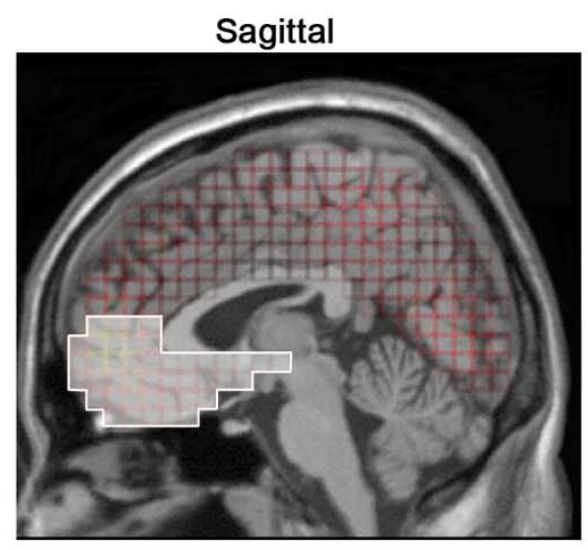

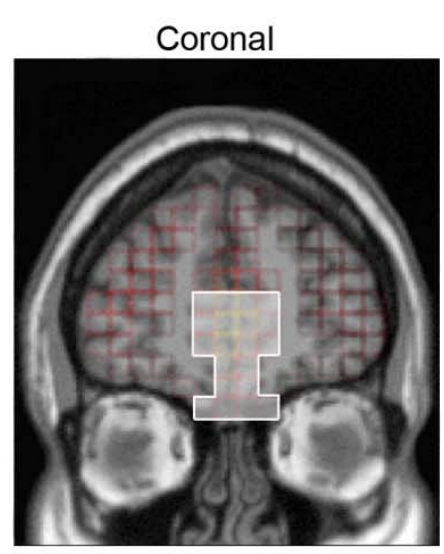

Axial
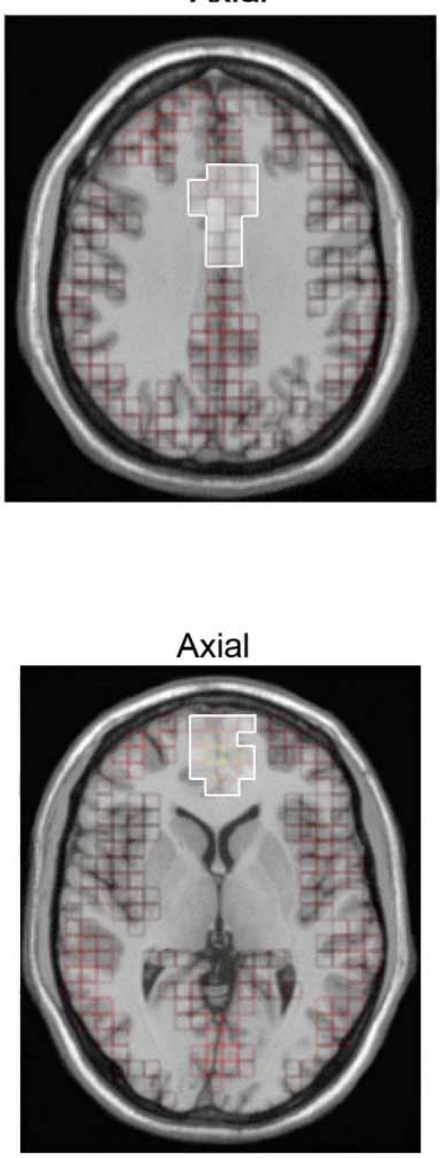

Figure 2. Dorsomedial and ventromedial regions of interest. 


\section{Dorsolateral ROI}
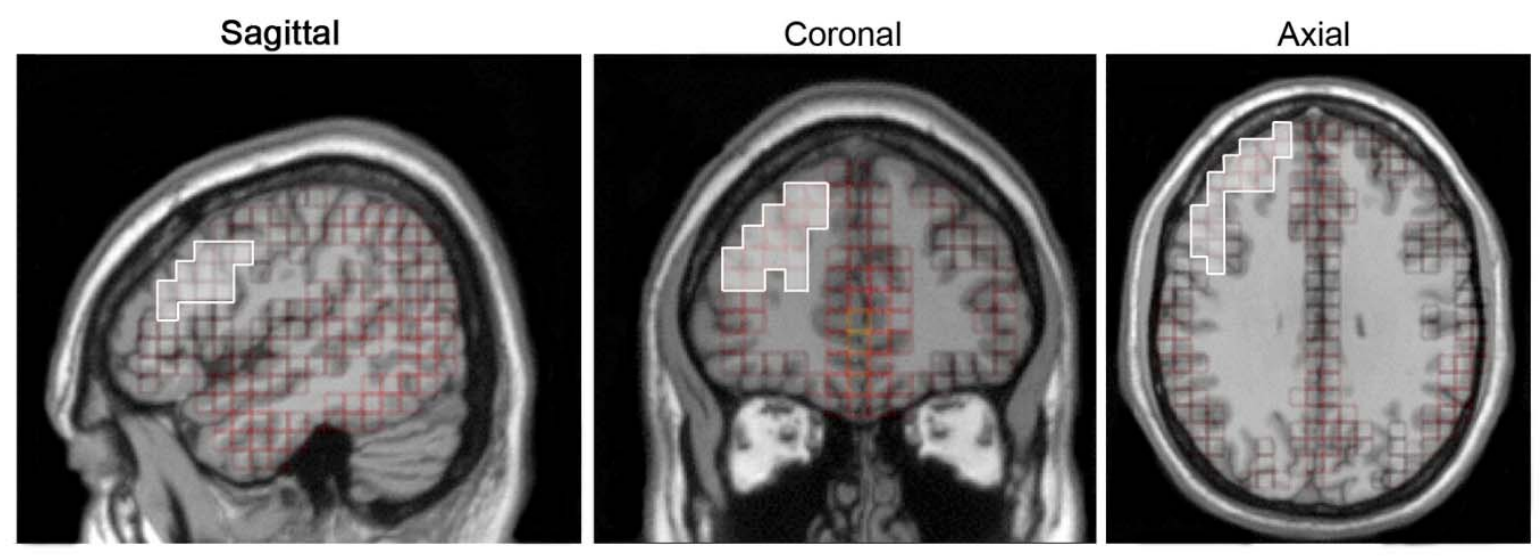

\section{Ventrolateral ROI}
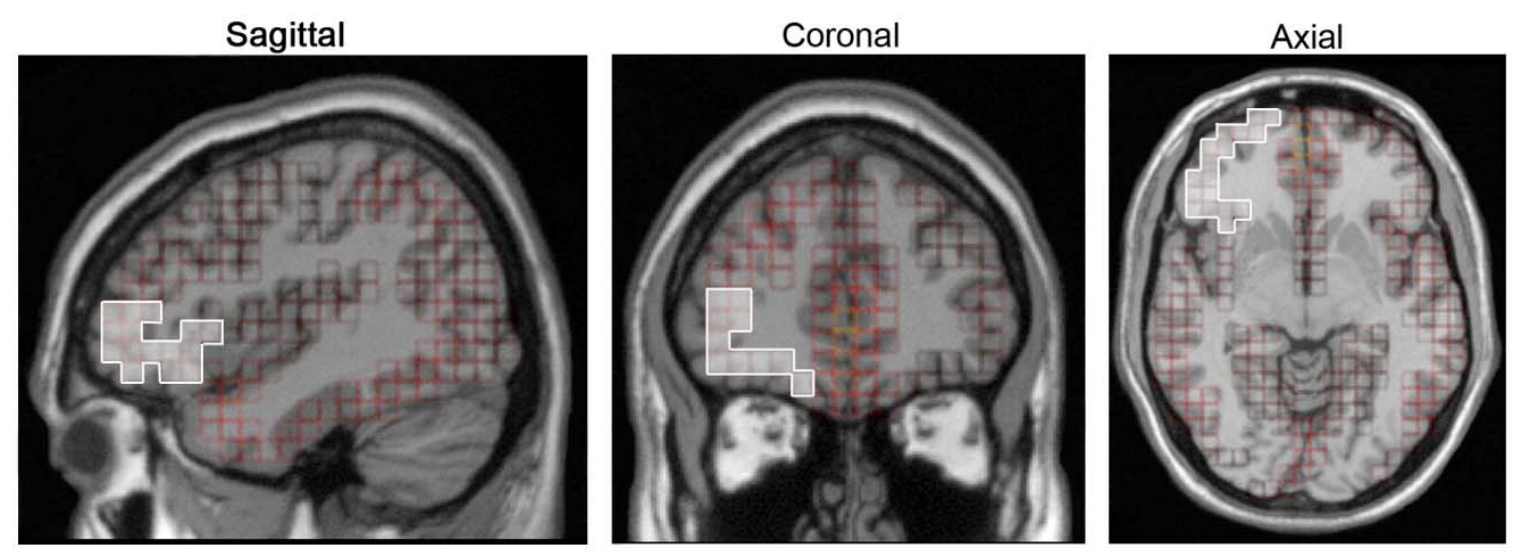

\section{Anterior Medialtemp ROI}
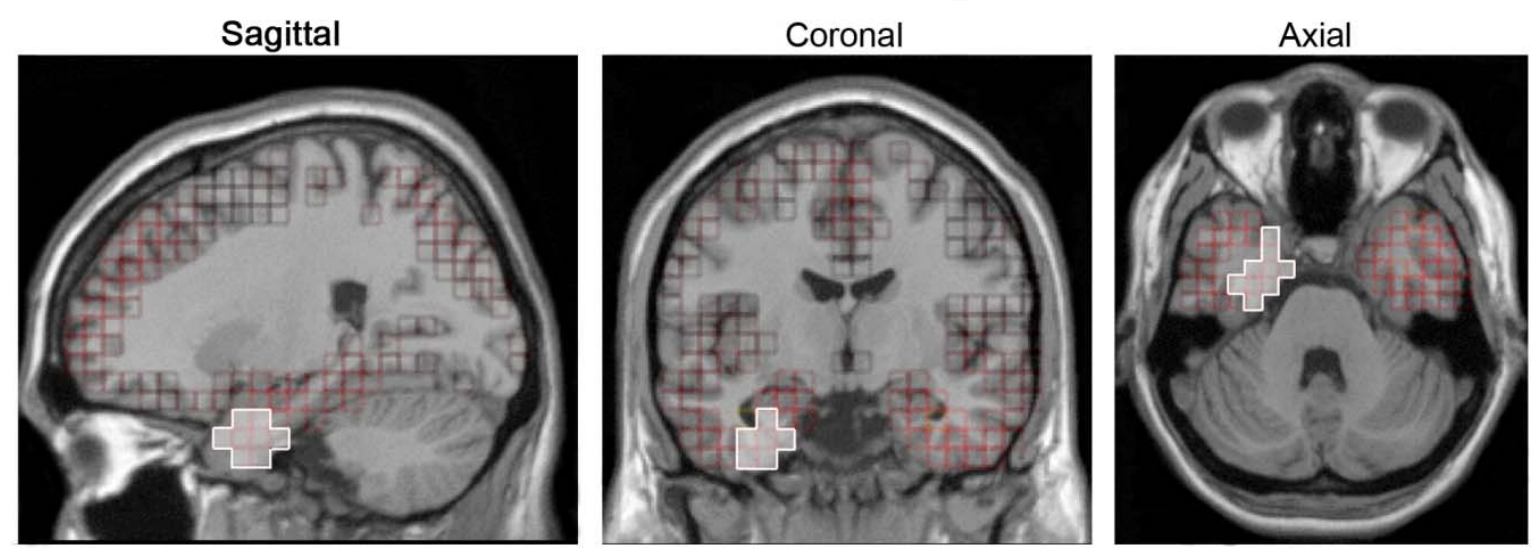

Figure 3. Dorsolateral PFC, ventrolateral PFC, and anterior medial temporal lobe ROls. PFC, prefrontal cortex; ROls, regions of interest. 


\subsection{Control for practice effects}

To ascertain whether results could be ascribed to repeated exposure to the task, I re-tested a subset of our comparison group 3 months after their first visit. As in a previous study using the same task (Lewis et al, 2008), results suggested that there were minimal practice effects on the neural measures. Specifically, a group of 14 nonclinical children 8-12 years old were assessed on two sessions 13 weeks apart - a similar lag to that of the clinical group. This group was not intended as a control group through which to ascertain the effects of treatment or an alternative on a nonclinical population, but was meant to estimate practice and exposure effects resulting from the repeated administration of the task. As noted before, the primary objective for this study was not to investigate the effectiveness of the treatment, per se, but rather to look at the neural correlates of individual differences in treatment response.

A 2 (Session) x 2 (Block) repeated-measures ANCOVA, controlling for age, gender, and trial count, was conducted, and it revealed that the comparison group did not differ by session in their N2 values. N2 magnitudes for the comparison group were relatively low compared to those of the clinical group and stayed at a similar level over time.

To investigate practice effects in both clinical and comparison groups on the behavioural measures, a 2 (Session) $\times 2$ (Block) x 3 (Group) repeated-measures ANOVA was conducted. Results show a significant Session $x$ Group interaction, $F(2,78)$ $=3.36, p<.05$, for Accuracy scores. Contrasts revealed that all groups significantly 
increased their accuracy rates $(p<.005)$. The comparison group was not significantly different from the clinical group at the pre session (See Table 4 for means and standard deviations).

\subsection{Statistical analysis}

Unless otherwise mentioned, the effects of age, gender, trial count (EEG only), and medication were covaried out of each analysis. Waveforms derived from less than 10 trials (for rationale, see Olvet \& Hajcak, 2009), as well as amplitude values with standard deviations larger than 3, at the sample level, were not analyzed. All EEG analyses were conducted on stimulus-locked waveforms from correct no-go trials in blocks $A$ and C. Partial Eta-squared values $\left(\eta^{2}\right)$ were computed to ascertain effect size. According to Vacha-Haase \& Thompson, (2004), $\eta^{2}=.01$ corresponds to a small effect, $\eta^{2}=.10$ corresponds to a medium effect, and $\eta^{2}=.25$ represents a large effect. 


\section{CHAPTER 3}

Results

\subsection{Behavioural results}

A 2(Session: pre vs. post) x 2(Group: improvers vs. nonimprovers) x 3(Block: A vs. B vs. C) mixed-model ANOVA was conducted for go/no-go performance accuracy and for go response time. A Session x Group interaction was found, whereby improvers showed greater increases in accuracy from pre- to post-treatment than nonimprovers, $F$ $(1,65)=5.53, p=.02$, partial $\eta^{2}=.08$. Collapsing across blocks, improvers had lower accuracy scores than nonimprovers before treatment $(p=.001)$ but not after treatment $(p=.68)$. No differences were found for accuracy between the clinical and the comparison groups before or after treatment.

The go response time data showed a main effect of session, $F(1,66)=14.06, p$ $<.001$, partial $\eta 2=.18$, whereby participants were faster at the post session. A significant main effect of block, $F(2,65)=3.15, p=.05$, partial $\eta^{2}=.09$, was found as well. Planned contrasts revealed faster response times in block $\mathrm{B}$, as expected $(p<.001)$. Response times were also faster in block $C$ than block $A(p<.001)$, perhaps due to a practice effect over the duration of the task. No differences were found between improvers and nonimprovers before or after treatment. Yet, the clinical sample was significantly slower than the comparison group before $(p=.03)$ and after treatment $(p=.01)$. Table 4 shows means and standard deviations for the behavioural data. 
Table 4: Means (and standard deviations) for behavioral data for clinical and comparison group

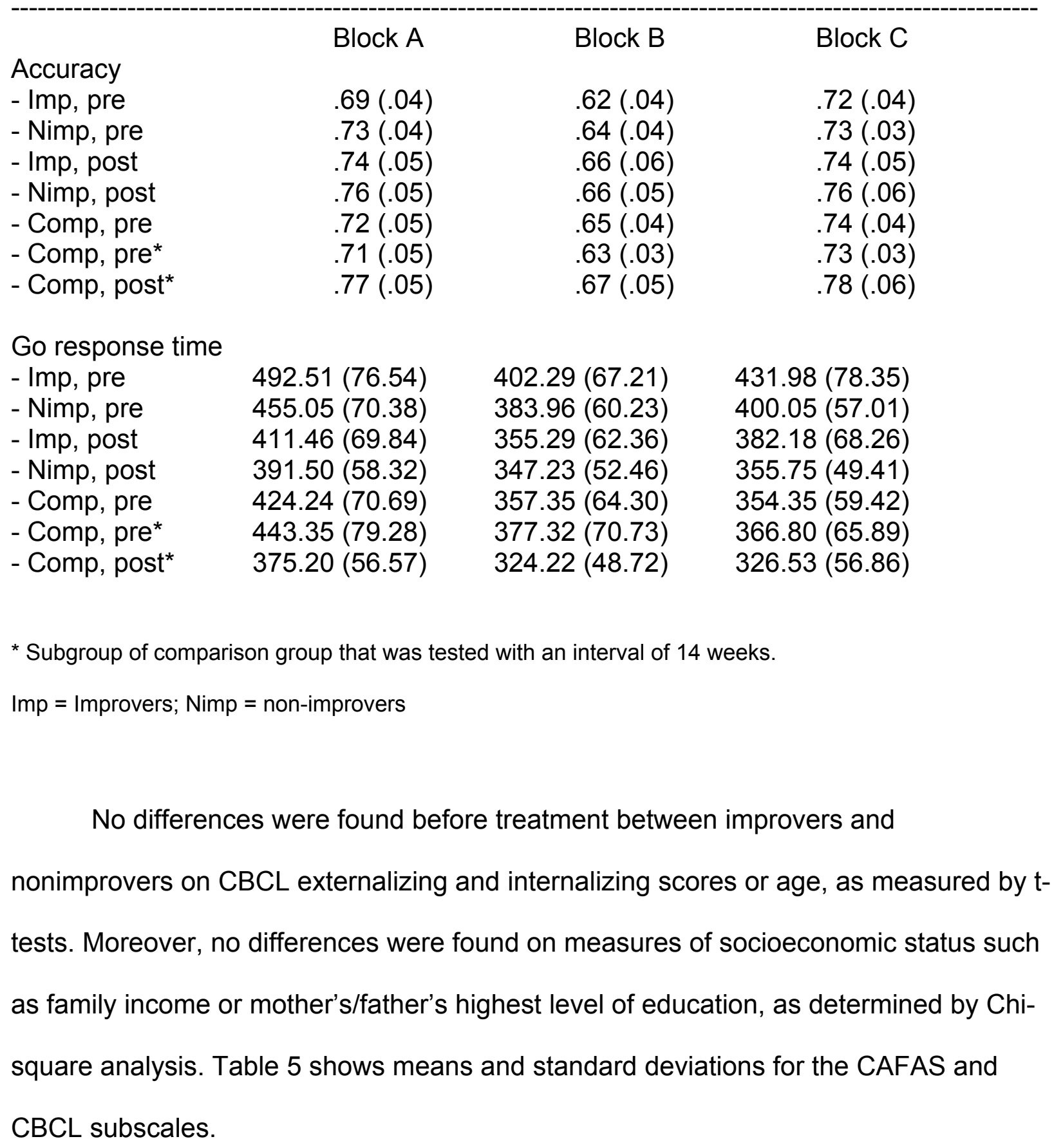


Table 5: Means and Standard deviations of clinical measures ( $p$-values and effect sizes are provided to indicate differences between pre and post-treatment).

$\begin{array}{lllll}\text { Improvers }(\mathrm{n}=32) & \text { Pre-treatment } & \text { Post-treatment } & \text { p-value } & \text { partial } \eta^{2} \\ \text { CAFAS Ext. } & 55.7(19.4) & 24.3(17.4) & <.001 & .19 \\ \text { CBCL Ext. } & 71.1(7.1) & 64.6(8.9) & .001 & .08 \\ \text { CBCL Int. } & 63.2(10.8) & 60.1(11.4) & .10 & .02\end{array}$

Nonlmprovers $(n=39)$

CAFAS Ext.

CBCL Ext.

CBCL Int.
$41.8(24.3)$

$70.3(5.6)$

$62.6(9.3)$
$45.6(26.9)$

$66.5(7.8)$

$58.7(10.1)$
.49

.02

.24
.004

.04

.01

Ext $=$ Externalizing scales; Int $=$ Internalizing scales .

The improver/nonimprover grouping as an indicator of SR-ability received additional support by the computation of a behavioural measure indicating resiliency in the face of stressors. Specifically, a ratio between pre and post accuracy scores, only from the frustrating B block, was used to estimate change in SR ability. Controlling for age, improvers performed significantly better than nonimprovers from pre- to posttreatment in block $B, F(1,67)=9.26, p=.003$, partial $\eta^{2}=.12$. This could imply that improvers were showing more relative improvement in their accuracy from pre to posttreatment than the non-improvers.

\subsection{ERP results: Clinical versus Comparison group}

Our clinical sample, before treatment had begun, showed larger N2 magnitudes than the comparison group, $F(1,86)=9.34, p=.003$, partial $\eta^{2}=.10$, as calculated by a 2(Group: clinical vs. comparison) x 2(Block: A vs. C) mixed-model ANOVA. A similar 
analysis revealed smaller frontal P3 magnitudes for the clinical sample, $F(1,86)=5.61$, $p=.02$, partial $\eta^{2}=.06$. The $\mathrm{N} 2$ did not significantly correlate with the frontal P3, suggesting they may reflect different and/or independent processes. No significant differences were found for the N1 or P2 (note that these were scored at the same site), nor were there any effects of block. These findings, consistent with the predictions, were indicate differences in prefrontal activation related to differences in SR between children with externalizing problems and their age-matched peers.

\subsection{ERP results: pre vs. post-treatment}

A 2(Session: pre vs. post) x 2(Group: improvers vs. nonimprovers) $\times 2$ (Block: A vs. C) mixed-model ANOVA revealed no significant effects for the N1 or P2 components, nor was there an effect of block. The frontal P3 showed a trend level Session $x$ Group interaction, $F(1,54)=2.86, p<.10$. However, none of the differences between improvers and nonimprovers reached significance, as shown by planned contrasts. Before treatment, no significant differences were found between improvers and nonimprovers in frontal P3 magnitudes.

A significant Session $x$ Group interaction, however, was found for the N2, $F(1$, $54)=5.87, p=.02$, partial $\eta^{2}=.10$. Planned contrasts showed a marked decrease in N2 magnitudes for improvers $(p=.002)$ compared to nonimprovers $(p=.82)$, suggesting that reduced cortical resources were dedicated to regulating impulses following successful treatment. No significant differences were found between improvers and nonimprovers on the $\mathrm{N} 2$ magnitudes prior to treatment $(p=.92)$. At post-treatment, nonimprovers showed significantly larger N2 magnitudes compared to the improvers $(p=.016)$ and 
compared to the subset of comparison children who completed a second assessment ( $p$ $=.005)$. Improvers were not different from Comparison group children $(p=.23)$ at posttreatment. Figures 4 and 5 show N2 amplitude values and waveforms for improvers and nonimprovers before and after treatment. Table 6 shows the means and standard deviations for N2 and frontal P3 measures before and after treatment. 


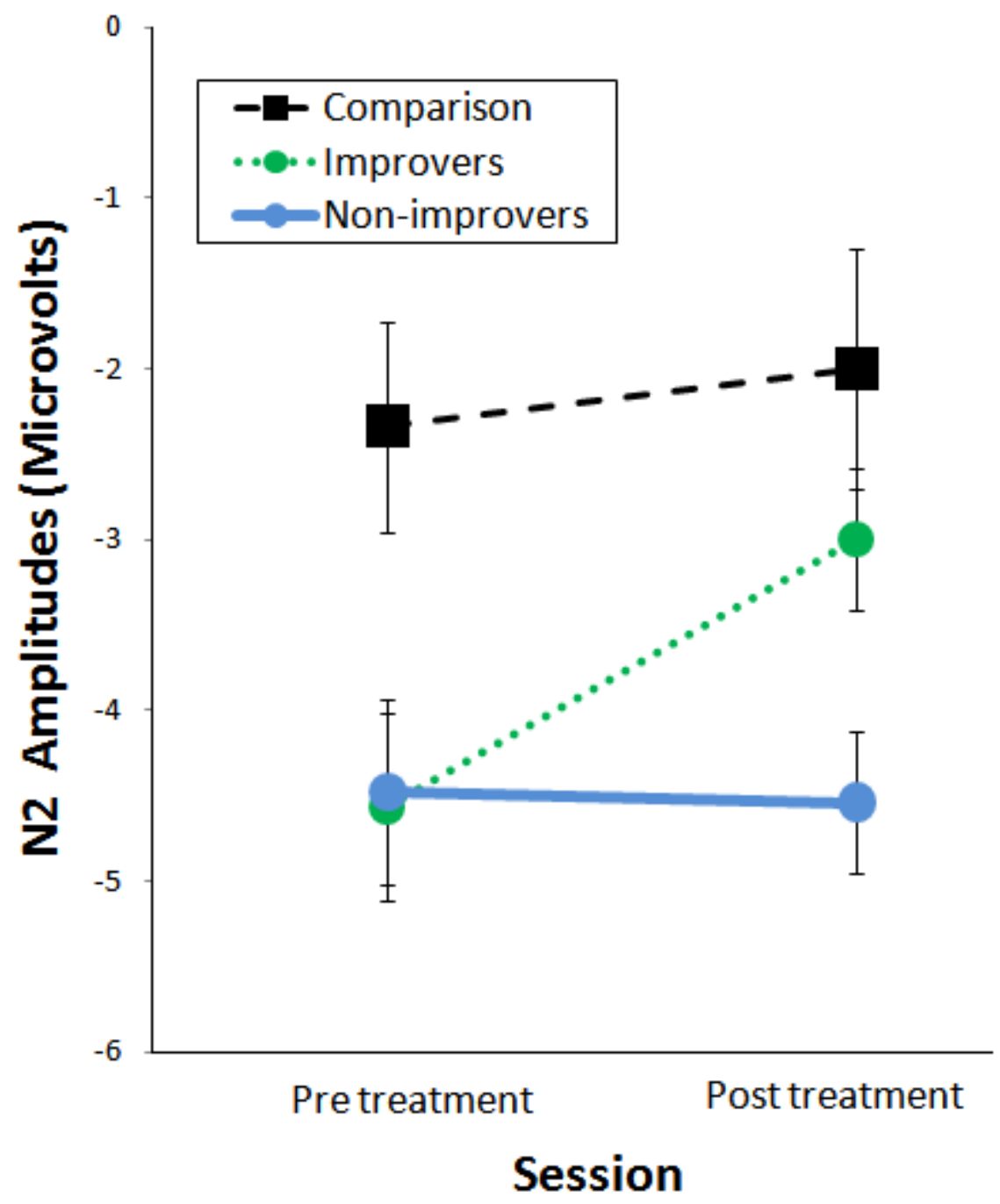

Figure 4. The N2 results at pre- and post-treatment. Group differences in N2 amplitudes were found between pre- and post-treatment. The comparison group is indicated for illustrative purposes. Note that larger N2 magnitudes correspond to greater negativity. 


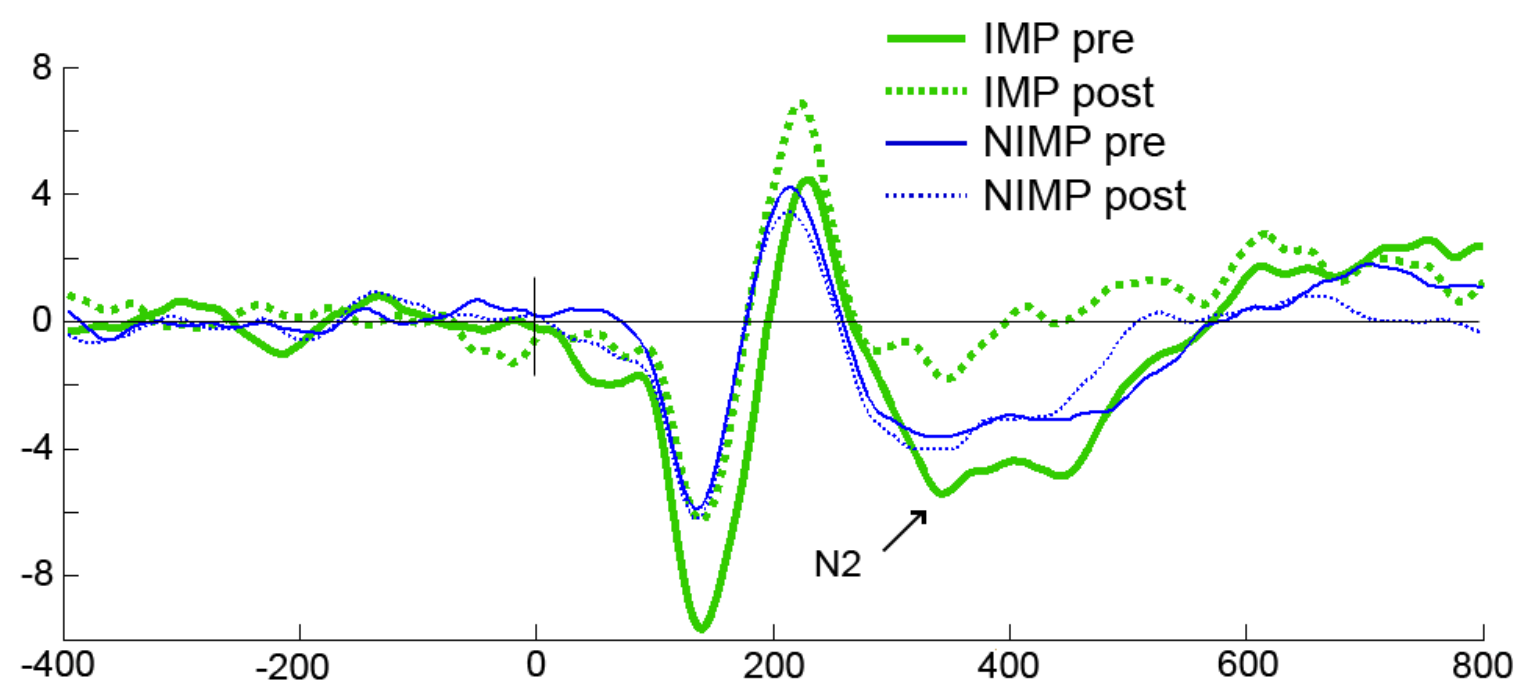

Figure 5. Grand-averaged stimulus-locked correct no-go ERP waveforms, collapsed across block $\mathrm{A}$ and $\mathrm{C}$ for improvers (IMPs) at pre- and post-treatment at site FCz. NIMP, nonimprovers; Pre, pre-treatment; Post, post-treatment. 
Correlating difference scores from pre to post-treatment for both CAFAS and N2 values showed decreases in N2 magnitudes to be correlated, at a trend level, to greater clinical improvements, $r(58)=-.23, p=.07$. Furthermore, decreases in N2 magnitudes, specifically those in block $A$, were correlated with accuracy improvements in block $B, r$ $(61)=-.28, p=.02$.

In sum, the data suggest that the N2 component was sensitive to treatment, but perceptual components such as the N1 and P2 were not. The frontal P3 did not show strong treatment effects either. 
Table 6: Mean amplitudes (and standard deviations) in microvolts for ERP data for clinical and comparison groups for blocks $\mathrm{A}$ and $\mathrm{C}$

\begin{tabular}{|c|c|c|}
\hline & Block A & Block C \\
\hline \multicolumn{3}{|l|}{$\mathrm{N} 2$} \\
\hline - Imp, pre & $-5.02(4.54)$ & $-4.84(4.12)$ \\
\hline - Imp, post & $-3.10(3.03)$ & $-3.38(2.90)$ \\
\hline - Nimp, pre & $-4.02(2.94)$ & $-3.91(2.85)$ \\
\hline - Nimp, post & $-4.20(2.30)$ & $-4.07(2.54)$ \\
\hline - Comp, pre & $-2.25(2.59)$ & $-3.18(2.34)$ \\
\hline - Comp, pre* & $-2.81(2.77)$ & $-3.34(2.83)$ \\
\hline - Comp, post* & $-2.66(1.98)$ & $-2.44(1.10)$ \\
\hline \multicolumn{3}{|l|}{ Frontal P3 } \\
\hline - Imp, pre & $.20(2.12)$ & $-.32(2.23)$ \\
\hline - Imp, post & .57 (1.47) & $.38(1.23)$ \\
\hline - Nimp, pre & .56 (1.99) & .67 (1.58) \\
\hline - Nimp, post & .02 (1.63) & .23 (1.97) \\
\hline - Comp, pre & $1.33(2.35)$ & $1.04(1.72)$ \\
\hline - Comp, pre* & $1.51(2.84)$ & $1.22(1.83)$ \\
\hline - Comp, post* & $.92(1.73)$ & $.46(1.76)$ \\
\hline
\end{tabular}

\subsection{Source model results}

For each ROI mean activation value, a 2(Session: pre vs. post) x 2(Group: improver vs. nonimprovers) x 2(Block: A vs. C) mixed-model ANOVA was run. Activation estimates for the dorsomedial ROI (suggesting dorsal ACC) showed a Session $x$ Group interaction, $F(1,42)=4.32, p=.04$, partial $\eta^{2}=.09$, with activation decreasing for improvers $(p=.004)$ and not for nonimprovers $(p=.92)$. Contrary to predictions, no significant Session $\times$ Group interaction was found for the ventromedial 
$\mathrm{ROI}(p=.52)$. However, because I specifically hypothesized a decrease in activation with successful treatment for this ROI, I was justified in investigating the planned contrasts. Indeed, a decrease in activation for improvers was found $(p=.01)$.

Bilateral activation in dIPFC and VIPFC ROIs showed no significant or trend level differences for any of the main effects or interactions. Activation in the aMTL ROI revealed a trend level Session $x$ Group interaction, for both left aMTL, $F(1,40)=3.07, p$ $=.09$, and right aMTL, $F(1,40)=3.17, p=.08$. This pattern of results indicates reductions in activation in dorsomedial PFC, ventromedial PFC, and medial temporal areas for improvers, whereas activation levels for nonimprovers stayed the same. 


\section{CHAPTER 4}

\section{Discussion}

The present thesis found changes in neural correlates of self-regulation in children with externalizing behaviour problems who improved with treatment. Children with externalizing behaviour problems showed larger N2 magnitudes and smaller frontal P3 magnitudes than the comparison group. Within the clinical group, children who improved following treatment demonstrated a marked decrease in the magnitude of the N2 in comparison with children who did not improve. Source analyses during the time period of the N2 estimated decreased activation in the ventromedial and dorsomedial PFC as well as the anterior medial temporal lobe in improvers only.

\subsection{Individual differences: clinical and comparison group.}

When the clinical and comparison groups were compared, it was first confirmed that larger N2 magnitudes and smaller frontal P3 magnitudes characterized the children who displayed clinical levels of externalizing behaviour problems. Consistent with other reports on medial frontal negativities, larger N2 magnitudes for the clinical sample would suggest a more effortful and less efficient style of response inhibition (Lamm et al., 2006; Lewis et al., 2008; Luu, Collins, \& Tucker, 2000). The smaller frontal P3 magnitudes, which were found for the clinical sample, have consistently been associated with a less efficient process of response control. No differences were found for early perceptual components such as the $\mathrm{N} 1$ and $\mathrm{P} 2$, indicating that cortical 
differences were specific to medial frontal ERPs implicated in cognitive control. These results confirmed the hypotheses, and support the notion that the N2 and frontal P3 are linked to cognitive processes related to SR.

No significant differences in behavioural accuracy during the go/no-go task were found between the clinical and comparison groups. The clinical group did show slower reaction times on go-responses compared to the comparison group, however, suggesting that children in the comparison group were able to respond faster without a loss of accuracy.

\subsection{Treatment effects: ERP and behavioural findings}

Next, I showed that behavioural and neural indices of SR changed with a successful response to treatment. At the neural level, treatment effects were specific to the N2, where decreases in activation were found for improvers. Perceptual components did not change with treatment. Although it was predicted that frontal P3 amplitudes would change with treatment, no changes were found for that component either. It is possible that this relatively late component marks a different phase of inhibition, such as the successful ending of the inhibitory process, which is not affected by treatment. Indices of cognitive processes involved in SR, such as the N2, found at earlier time periods did show a robust reduction with treatment. This finding suggests less internal conflict, or that reduced cortical resources were required to regulate impulses. The changes in these neural processes may reflect the development of a more efficient SR, which could explain the improvement in those children. 
Reductions in N2 activation have also been observed as children mature (Lewis et al, 2006), implying increased efficiency for inhibitory control when older children are challenged. The decrease of N2 activation with successful treatment of externalizing problem behaviour suggest a normalization in neural activation levels, as larger N2 magnitudes have been found to correspond with increased levels of response conflict and problem behaviour in children (Jonkman, van Melis, Kemner, \& Markus, 2007; Ladouceur et al., 2010).

The current study found scalp ERP effects following treatment where none were found in a former, similar study (Lewis et al., 2008). It is possible the larger sample size in the present study allowed for better detection of such differences. Another explanation is the use of regression-based artifact correction methods which were utilized in the present study. The latter could have led to more reliable waveforms due to a significant increase in trials and the (resulting) reduced number of participants excluded for insufficient trials. More information on the choice and merits of this approach can be found in section 2.5.2.

At the behavioural level, improvers, as determined by clinician and parent report measures, showed better accuracy following treatment than nonimprovers, especially during the frustration-inducing B block. These data suggest an improved ability to regulate task-focused behaviour, perhaps because participants are better able to stay on task in the face of frustration. This type of stress-resiliency is a key feature of SR.

In sum, these data provide neural and behavioural evidence that more effective self-regulatory mechanisms may help explain the beneficial effects of treatment for child behaviour problems. 


\subsection{Treatment effects: source analysis results}

Source analysis during the time-window of the N2 found reductions in activation in ventromedial PFC areas, including the ventral ACC and OFC, as well as the strongly connected paralimbic regions of the temporal lobe for improvers following treatment. The aMTL, including para-amygdalar regions such as the temporal pole and inferior temporal cortex, has recently been implicated in emotion regulation (Olson, Plotzker, \& Ezzyat, 2007) and processing (Bishop, 2007). Though it is unlikely that amygdala activity can be detected directly using EEG, it is possible para-amygdalar activity could be indicative of its functioning (e.g., rapid motivational salience processing). This pattern of results suggests changes in activation in regions associated with reactive SR (Ressler \& Mayberg, 2007; Rolls, 2004). A reduction in activation in these systems could reflect a more efficient processing of stimuli representing less response conflict, or a reduced need for effort allocated to processes of response monitoring.

No changes were found in the ventrolateral and dorsolateral ROIs, areas often associated with deliberate SR strategies (Ochsner et al., 2002). The reduction found for improvers in dorsomedial PFC activation, often associated with deliberate SR, is at odds with our hypotheses predicting no change in activation in this region (see also, Lewis et al., 2008). It is possible that the reduction in dorsomedial PFC activation, typically associated with deliberate SR, could reflect a reduced need for cognitive support when ventral systems are doing their job more effectively in the first place. Consistent with studies on working memory, this view implies prefrontal regions to be 
strongly connected and to support each other when demands are high (Rypma, Berger, \& D’Esposito, 2002).

These findings replicated the results of an earlier study with respect to reductions in ventromedial PFC activation, but not with respect to dorsomedial activation, which in the previous study remained unchanged for both improvers and nonimprovers following treatment (Lewis et al, 2008). One way to explain this discrepancy is that the increase in the sample size in the present study allowed for a better ability to detect differences. Another possibility is that the form of treatment provided by the agencies has changed over the years, so that different patterns of brain activation are associated with successful change. Though speculative, it may be that an increased emphasis on therapeutic strategies that aim treatment at both deliberate and reactive control processes could have caused a change in dorsomedial PFC regions.

\subsection{Neural hubs of Self-Regulation: the ACC}

A recent publication by Shackman et al., (2011) reviewed studies investigating the role of the ACC in cognitive control using imaging, anatomical, and computational modeling, and challenged the view of independent, and clearly functionally distinct, dorsal and ventral ACC regions. The authors concluded that the ACC should be seen as a hub, responsible for the regulation of affect as well as goal-directed behaviour. Although counter to my initial hypothesis, this perspective could explain the reduced activation in ventral and dorsal ACC following treatment in the present study. SR, indeed, often involves reactive as well as deliberate types of control, and these do not operate in isolation. The ACC could be central in mediating elements of deliberate as 
well as reactive SR (Lewis \& Todd, 2007; Pessoa, 2008; Woltering \& Lewis, 2009). I will next provide arguments for the ACC's role in the coordination of reactive and deliberate SR.

First, the ACC is a paralimbic structure located in the center of the brain. As opposed to most other cortical structures (and those in other species), the ACC contains long-distance "spindle cells" thought to promote coordination between regions in humans (Allman, Hakeem, Erwin, Nimchinsky, \& Hof, 2006). For example, the ACC lies adjacent to lower-level limbic structures associated with reactive SR as well as the structures in the prefrontal cortex associated with deliberate SR. Second, as mentioned before, the ACC seems to consist of a more cognitive dorsal component and a more emotional ventral component, referred to as "cognitive" and "affective subdivisions," making it ideally suited to assume an integrative role (Bush et al., 2000). The ACC is intricately connected to the dIPFC, subserving working memory and decision making (Petrides \& Pandya, 2001), as well as the OFC, amygdala, hypothalamus, and brain stem, subserving more immediate emotional concerns. The OFC, for example, has been implicated in more emotion-driven influences on action selection (Bechara, Damasio, \& Damasio, 2000). Thus, the function of the ACC, in a dynamic interplay of its ventral and dorsal divisions, can be to direct other systems involved in emotion regulation, acting as an epicenter for multiple self-regulatory processes. For example, the dorsal ACC is thought to play a role in maintaining working memory and to regulate executive processes involving planning, self-monitoring, and conscious control (Paus, 2001), whereas the ventral ACC has been thought to directly influence structures mediating emotional responses, behavioural routines, and the physiological states 
necessary to support them (Chapman, Woltering, Lamm, \& Lewis, 2010; Critchley et al., 2003; Pezawas et al., 2005). Third, the ACC is involved in conflict detection or (error) monitoring. This is a crucial step in directing regulation processes, as the ACC may signal the need for further processing by either ventral systems or lateral and dorsal prefrontal regions when demands are high. Indeed, studies find increased ACC activation in challenging situations when subjects need to select among alternative responses, shift attention, and alter behavioural strategies (Posner \& Rothbart, 2000; van Veen \& Carter, 2002). Last, from a developmental perspective, studies of grey matter density reveal that the ACC and OFC begin to develop later than the amygdala, brain stem, and hypothalamus, but earlier than the dIPFC and vIPFC regions implicated in deliberate control (Giedd et al., 1999; Gogtay et al., 2004; Rubia et al., 2000). Importantly, all these regions continue to mature throughout life. However, a recent study found that the ACC is one of the last cortical regions to reach its peak in grey matter density (Shaw et al., 2008), suggesting ongoing development of its role in integration and coordination. According to some investigators, deliberate SR becomes mediated by dorsal ACC networks at about the age of 3 years (Posner \& Rothbart, 2000). Indeed, children around that age are better at controlling impulses (Jones, Rothbart, \& Posner, 2003). Slightly older children begin to use higher-order rule systems and other executive functions, mediated by dorsal ACC, that are thought to underlie the regulation of attention and emotion (Lamm et al., 2006; Zelazo \& Müller, 2002). These data support the notion that brain systems underlying reactive SR develop earlier than those underlying deliberate SR. However, this does not mean that their development is independent. The connectedness between brain systems in the ACC is 
particularly interesting in relation to the hierarchical nature of the functions assumed by its "cognitive" and "affective subdivisions" (Bush et al., 2000).

A developmental account implies that the different ventral and dorsal ACC systems do not mature in isolation, but that they instead build on each other, demonstrating ongoing reciprocal influences between neural networks across development. This resonates well with Mark Johnson's (2001) hypothesis concerning interactive specialization, which states that the emergence of new skills depends on the coupling of already functioning regions. Systems can then be seen as entraining each other (Bressler \& Kelso, 2001). This coordination between regions drives the development of advancing skills. An efficient coordination between reactive and later-developing deliberate brain systems can then be seen as the expression of a general developmental principle, but one that has unique significance for the developmental trajectory of SR. As a consequence, deficiencies in reactive SR would be expected to have a negative impact on the development of deliberate SR, with potentially major consequences for the overall effectiveness of SR. And so, it is possible that deliberate SR, mediated by the dorsal ACC, builds directly on anatomical and functional links with the ventral ACC, involved in reactive SR (Ray \& Zald, 2011), and that these systems become increasingly integrated with age.

\subsection{The role of anxiety in aggression}

An important observation with respect to our sample of externalizing children is the remarkably high level of internalizing problems. This comorbidity was reported to be 
a general phenomenon in a recent review by Bubier and Drabick (2009), and it may be relevant for interpreting the neural results. First, medial frontal negativities related to the N2, such as the Error Related Negativity (ERN, a response-locked waveform), show large medial frontal negativities associated with anxiety spectrum disorders (Hajcak, McDonald, \& Simons, 2003; Ladouceur, Dahl, Birmaher, Axelson, \& Ryan, 2006). Second, the heightened activity in ventromedial PFC and paralimbic regions in our clinical sample seems to be consistent with other imaging studies in anxious populations that found overactive limbic and paralimbic circuits to be associated with ineffective reactive SR involving rapid, threat-focused attentional biases (Bishop, 2007). Last, treatment studies with anxious populations have shown activation reductions in similar brain systems (Bryant et al., 2008; Ressler \& Mayberg, 2007). Activity reduction in these systems, as found in the present study in children who improved with treatment, could indicate that this neural system, and the socio-emotional behaviors it mediates, has normalized. Though this is speculative, it is possible that the overactivity in neural systems involved in SR could underlie the large degree of internalizing problem behavior detected in these children, and could explain the tension they bring to social situations-a tension that eventually manifests in aggressive outbursts.

The work of John Dollard (1939) offered an early framework for this 'anxiety hypothesis of aggression'. Dollard proposed that aggression occurs because blocked goals would lead to a state of frustration which could lead to aggression in order to resolve this uncomfortable state. It is possible that anxiety leads to/results from an increased risk of frustration that can underlie externalizing behavior problems in a large subset of children. Anxious individuals are known to cling to predictable behavioral 
patterns and thoughts that provide them with a sense of control. This perceived control can become so important that it becomes a goal in itself. But since (social) life is full of events that are beyond one's own control, such as other people's opinions about you, rapidly shifting group dynamics, and unexpected mood swings of oneself and caregivers, it is easy to feel a loss of control. Together with a negative threat-focused bias, anxious children could have a greater propensity for becoming frustrated because more events are perceived as threatening, blocking goals of safety and control. Frustration can then build up and may result in aggression.

Whether aggression occurs may depend on a child's learned behavioral response style, the intensity of the frustration, and a child's self-regulatory capacity. The latter, which is almost synonymous with one's capacity for emotion regulation, can be seen as an exhaustible resource in this case. SR, then, is like a muscle that can get tired when overused and impact any subsequent mental activity requiring SR. This concept is referred to as ego depletion (Baumeister, Bratslavsky, Muraven, \& Tice, 1998) and could, in the context of an anxiety hypothesis of aggression, serve as a basis for further hypothesis testing.

\subsection{Limitations and important considerations}

\subsubsection{Assessing the effects of treatment without a control group}

I need to emphasize that the current study was not intended, nor conducted, as a randomized control trial. My primary interest was to look at within-subject differences in the response to treatment rather than in differences in treatment type or delivery. Thus, the clinical population functioned as their own 'control'. However, the likelihood of 
outcome differences primarily resulting from trivial factors was limited. Specifically, I showed that cortical activation differences were not solely due to practice effects by testing a comparison group across the same time interval. Furthermore, no differences were found between improvers and nonimprovers before treatment on variables such as problem behaviour, suggesting that the differences we found in brain and behaviour depended on the response to treatment. Moreover, the finding that the degree of improvement with treatment correlates with changes in N2 values suggests that treatment could be an important factor in explaining the differences. Regardless, the implications of this study for treatment effects must be taken as suggestive rather than definitive.

\subsubsection{Validating the distinction between deliberate and reactive Self-Regulation.}

Another limitation is the lack of a behavioural or questionnaire measure to validate the distinction of deliberate and reactive types or SR. Although this distinction mostly relates to the neural model that was presented in the current thesis, and could be suggestive of changes in particular types of control, it would have strengthened the current study if some well-validated measures had been utilized to actually measure the type of improvement in behavioural measurements. Furthermore, changes in deliberate types of SR could be inadequately measured in the current paradigm as it is possible that the rapid, bottom-up nature of the go/no-go task simply did not elicit slower reappraisal processes. The distinction therefore remains more theoretical than practical, but, as mentioned before, could lead to future hypothesis testing. 


\subsubsection{Methodological notes on source analysis.}

It needs to be stressed that the results with respect to the source analysis should be interpreted with caution. Source-space analyses estimating the location of cortical sources are based on an inverse modeling of activation measured at many scalp electrodes. This inverse modeling is considered an "ill posed" problem as the number of possible solutions is far greater than the number of preset constraints. Assumptions underlying the solution involve uncertainties that can create measurement errors (see Michel et al, 2004, for overview). Moreover, the lab did not have resources to ascertain each child's MRI and average age-specific MRI head models are not yet available. Thus, even though superimposing children's cortical activation over an adult MRI is by no means ideal, this is the current standard. This was one of the reasons why the ROls included such broad regions. In the future, more fine grained anatomical analysis using EEG technology may be possible using either the child's own MRI (which is the best scenario) or age-specific MRI head models.

\subsubsection{Limitations in clinical diagnoses and assessments}

A further limitation of the study is the lack of formal clinical measures of IQ and diagnoses in accordance with DSM-IV criteria for conduct disorder, oppositional defiant disorder, ADHD, and mood disorders. This was a limitation that was hard to remedy for practical reasons. To ensure that our results were relevant to "real world" practice, the study was conducted in partnership with community-based child and family agencies that implement evidence-based interventions. As a result, the study was constrained to the protocols that these agencies already had in place. Children referred for treatment to these agencies did not regularly undergo full psychiatric assessments. Instead, a 
battery of standardized measures was used to assess children's and parents' clinicallyrelevant symptoms and functioning.

A total of 15 participants $(\sim 20 \%)$ in our sample did have a diagnosis of ADHD as reported by the parent. Removing these 15 participants from the sample did not change the outcome of the results. For example, a similar pattern emerged for improvers and nonimprovers for reductions in N2 amplitudes when I observed just the group remaining after removal of the comorbid ADHD group.

To test for the effect of mood symptoms, I performed an additional analysis. The DSM Affective problems score of the $\mathrm{CBCL}$, an indicator of mood regulation problems, showed no difference between IMPs (mean T-score $=64$, sd $=8.3$ ) and NIMPs (mean T-score $=64, s d=9.7)$, on t-tests $(p=.80)$. Furthermore, excluding children who scored above the clinical range (T-scores $>70$ ) for affective problems also did not yield a different pattern of results. Children with ADHD symptoms, mood symptoms, or children who have parents with mood disorders were not excluded, however, as such symptoms could be aspects of the overall behavioral problems that brought them into treatment.

Another concern was whether the outcomes of treatment were due to factors such as IQ. Although executive tasks were not a focus of this thesis, the WAIS forwards and backwards digit span was administered when the children visited. When an average of the forwards and backwards digit span tasks was taken as an approximation of $I Q$, no differences were found before treatment between improvers and nonimprovers. 


\subsubsection{Effects of task block: the emotion induction}

Last, it's unfortunate that ERP data from block B could not be analyzed, mainly due to insufficient trials, as this data could have provided a window into how activation patterns change in the time frame immediately corresponding to emotional challenge across the treatment period. The remaining blocks, however, were also challenging and

filled with emotional investment, although to a lesser degree. The children were told that they needed to get a lot of points in order to get a big prize. If they were unable to get enough points (an unknown number that the computer would "decide") they would have to choose from a toy bin with small, and less desirable, toys. Children rated blocks $A$ and $\mathrm{C}$ to be mildly stressful in comparison to block $\mathrm{B}$, which was felt to be far more stressful.

Blocks $\mathrm{A}$ and $\mathrm{C}$ were structurally identical; however, a separate analysis of the blocks could reveal differences in brain activation and behaviour. For example, one could argue that the majority of effects would be present in block $\mathrm{C}$, during which participants had to recruit greater executive attention resources to "recover" from block B. However, no such effects, or any other effects, of block were found in the comparison between block $\mathrm{A}$ and $\mathrm{C}$ in the present study. It is possible the actual 'recovery period' during block $\mathrm{C}$ was too brief to have a measurable effect.

\subsection{Significance, implications, and future directions.}

The present thesis may be valuable in several ways. First, translational research attempting to bridge the gap between neuroscience and clinical practice is challenging and therefore rarely conducted. One of the most significant problems, and a common 
source of misunderstanding, is the conflation of levels of analysis. Activation patterns in the brain do not directly translate to general psychological constructs such as emotion regulation. And to make matters worse, for practical reasons, neuroscientists often do not study psychological constructs directly but focus on testing specific cognitive processes in isolation. For example, underlying the capacity for emotion regulation is assumed to be a suite of basic - lower level - cognitive processes such as inhibitory control, error monitoring, and goal setting. However, such assumptions may themselves require validation. These and other considerations make translational research a timeconsuming area, which must rely on multiple, hypothesis-driven studies that can confirm or reject its assumptions. One way that science progresses is by finding patterns at one level and making predictions at another, but those involved in clinical practice and intervention science are not always aware of, nor willing to wait for, such developments. Second, investigating biological correlates of behaviour can lead to unique insights. As individual differences in emotion regulation become deeply entrenched, they reliably predict psychopathological outcomes, and they become increasingly resistant to intervention as people mature. Most investigators question whether different styles of SR reflect distinct biological mechanisms. However, behavioural research cannot measure these mechanisms. Research with adults has made progress linking executive functions to activation profiles of distinct brain regions; however, developmental cognitive neuroscience is only beginning to tackle emotion and SR. Moreover, intervention studies investigating neural activation associated with SR in child populations have been extremely rare. Since the acquisition of self-regulatory capabilities is grounded in the development of brain systems thought to mediate 
cognitive and emotional processes, neuroscientific research programs working in tandem with treatment programs serving a child population can provide important insights into the neural factors underlying successful SR development. The current study shows that children who improve with treatment demonstrate changes in areas associated with self-regulation. However, rather than experiencing specific difficulties in reactive SR, non-improvers may suffer from ineffective coordination between reactive and deliberate control systems as mediated by the ACC.

Though knowledge of the development and plasticity of SR is still scarce, accurately modeling this process and its neurological correlates can provide significant advantages in the long run. Neurally informed models of the development of selfregulatory capacities, in relation to clinical profiles, can guide research in new directions but also lay the groundwork for effective interventions by policy makers, schools, and parents.

\subsection{Conclusion}

To the best of my knowledge, this is the largest intervention study to date investigating the neural correlates of SR in a community sample of children with externalizing behaviour problems. The study provides support for the idea that cortical activation patterns underlying $\mathrm{SR}$, as well as behavioural performance mediated by these patterns, can change with successful treatment. The neural correlates of SR that were tested in this study may provide neural indices related to externalizing behaviour problems, or to the internalizing problems that can underlie them, and may help provide a more comprehensive understanding of differences in treatment efficacy. 


\section{REFERENCES}

Allman, J. M., Hakeem, A., Erwin, J. M., Nimchinsky, E., \& Hof, P. (2006). The Anterior Cingulate Cortex. Annals of the New York Academy of Sciences, 935, 107-117.

Amaral, D. G., Price, J. L., \& Pitkanen, A. (1992). Anatomical organization of the primate amygdaloid complex. In J. P. Aggleton (Ed.), The Amygdala: Neurobiological Aspects of Emotion, Memory, and Mental Dysfunction (pp. 1-66). Wiley-Liss.

Augimeri, L. K., Farrington, D. P., Koegl, C. J., \& Day, D. M. (2007). The SNAP ${ }^{T M}$ Under 12 Outreach Project: Effects of a Community Based Program for Children with Conduct Problems. Journal of Child and Family Studies, 16, 799-807.

Bar-Haim, Y., Lamy, D., Pergamin, L., Bakermans-Kranenburg, M. J., \& van IJzendoorn, M. H. (2007). Threat-related attentional bias in anxious and nonanxious individuals: a meta-analytic study. Psychological Bulletin, 133, 1-24.

Bargh, J. A., \& Ferguson, M. J. (2000). Beyond Behaviorism: On the Automaticity of Higher Mental Processes. Psychological Bulletin, 126(6), 925-945.

Barkley, R. A. (2000). Commentary on the multimodal treatment study of children with ADHD. Journal of Abnormal Child Psychology, 28, 595-599.

Baumeister, R. F., Bratslavsky, E., Muraven, M., \& Tice, D. M. (1998). Ego depletion: Is the active self a limited resource? Journal of Personality and Social Psychology, $74,1252-1265$.

Bechara, A., Damasio, A. R., Damasio, H., \& Anderson, S. W. (1994). Insensitivity to future consequences following damage to human prefrontal cortex. Cognition, 50, 7-15.

Bechara, A., Damasio, H., \& Damasio, A. R. (2000). Emotion, decision making and the orbitofrontal cortex. Cerebral Cortex, 10, 295-307.

Bekker, E. M., Kenemans, J. L., \& Verbaten, M. N. (2005). Source analysis of the N2 in a cued Go/NoGo task. Brain Research Cognitive Brain Research, 22, 221-231.

Belsky, J., Friedman, S. L., \& Hsieh, K. H. (2001). Testing a Core Emotion-Regulation Prediction: Does Early Attentional Persistence Moderate the Effect of Infant Negative Emotionality on Later Development? Child Development, 72, 123-133. 
Bishop, S. J. (2007). Neurocognitive mechanisms of anxiety: an integrative account. Trends in cognitive sciences, 11, 307-316.

Bloomquist, M., \& Schnell, S. (2002). Helping children with aggression and conduct problems: Best practises for intervention (p. 418). New York: Guildfort.

Bokura, H., Yamaguchi, S., \& Kobayashi, S. (2001). Electrophysiological correlates for response inhibition in a Go/NoGo task. Clinical Neurophysiology, 112, 2224-2232.

Bongers, I. L., Koot, H. M., van der Ende, J., \& Verhulst, F. C. (2008). Predicting young adult social functioning from developmental trajectories of externalizing behaviour. Psychological Medicine, 38, 989-999.

Borst, G., Thompson, W. L., \& Kosslyn, S. M. (2011). Understanding the dorsal and ventral systems of the human cerebral cortex: beyond dichotomies. The American Psychologist, 66, 624-32.

Bradley, S. (2003). Affect regulation and the development of psychopathology (p. 324). Guilford Press.

Braver, T. S., \& Barch, D. M. (2006). Extracting core components of cognitive control. Trends in Cognitive Sciences, 10, 529-32.

Bressler, S. L., \& Kelso, J. A. S. (2001). Cortical coordination dynamics and cognition. Trends in Cognitive Sciences, 5, 26-36.

Brestan, E. V., \& Eyberg, S. M. (1998). Effective psychosocial treatments of conductdisordered children and adolescents: 29 years, 82 studies, and 5,272 kids. Journal of Clinical Child Psychology, 27, 180-189.

Bryant, R. A, Felmingham, K., Kemp, A, Das, P., Hughes, G., Peduto, A, \& Williams, L. (2008). Amygdala and ventral anterior cingulate activation predicts treatment response to cognitive behaviour therapy for post-traumatic stress disorder. Psychological Medicine, 38, 555-561.

Bubier, J. L., \& Drabick, D. A. (2009). Co-occurring anxiety and disruptive behavior disorders: the roles of anxious symptoms, reactive aggression, and shared risk processes. Clinical Psychology Review, 29, 658-669.

Bunge, S. A. (2004). How we use rules to select actions: A review of evidence from cognitive neuroscience. Cognitive, Affective, \& Behavioral Neuroscience, 4, 564579

Bush, G., Luu, P., \& Posner, M. I. (2000). Cognitive and emotional influences in anterior cingulate cortex. Trends in Cognitive Sciences, 4, 215-222. 
Calkins, S. D., \& Dedmon, S. E. (2000). Physiological and behavioral regulation in twoyear-old children with aggressive/destructive behavior problems. Journal of abnormal child psychology, 28, 103-118.

Calkins, S. D., \& Fox, N. A. (2002). Self-regulatory processes in early personality development: a multilevel approach to the study of childhood social withdrawal and aggression. Development and psychopathology, 14, 477-98.

Calkins, S. D., \& Howse, R. B. (2004). Individual differences in self-regulation: Implications for childhood adjustment. In P. Philippot \& R. S. Feldman (Eds.), The regulation of emotion (pp. 307-332). Mahwah, NJ: Lawrence Erlbaum Associates.

Cappadocia, M. C., Desrocher, M., Pepler, D., \& Schroeder, J. H. (2009).

Contextualizing the neurobiology of conduct disorder in an emotion dysregulation framework. Clinical psychology review, 29, 506-518.

Casey, B. J., Trainor, R. J., Orendi, J. L., Nystrom, L. E., Giedd, J. N., Castellanos, X., Haxby, J. V., et al. (1997). A developmental functional mri study of prefrontal activation during performance of a go-no-go task. Journal of Cognitive Neuroscience, 9, 835-847.

Caspi, A. (1987). Personality in the life course. Journal of Personality and Social Psychology, 53, 1203-1213.

Chapman, H. A., Woltering, S., Lamm, C., \& Lewis, M. D. (2010). Hearts and minds: Coordination of neurocognitive and cardiovascular regulation in children and adolescents. Biololgical Psychology, 296-303.

Critchley, H. D., Mathias, C. J., Josephs, O., O’Doherty, J., Zanini, S., Dewar, B. K., Cipolotti, L., et al. (2003). Human cingulate cortex and autonomic control: Converging neuroimaging and clinical evidence. Brain, 2139-2152.

Crone, E. A, Wendelken, C., Donohue, S., van Leijenhorst, L., \& Bunge, S. A. (2006). Neurocognitive development of the ability to manipulate information in working memory. Proceedings of the National Academy of Sciences of the United States of America, 103, 9315-9320.

Cunningham, W. A, Van Bavel, J. J., \& Johnsen, I. R. (2008). Affective flexibility: evaluative processing goals shape amygdala activity. Psychological science: a journal of the American Psychological Society / APS, 19, 152-160.

Davidson, M. C., Amso, D., Anderson, L. C., \& Diamond, A. (2006). Development of cognitive control and executive functions from 4 to 13 years: evidence from manipulations of memory, inhibition, and task switching. Neuropsychologia, 44, 2037-2078. 
Davis, M., \& Shi, C. (2000). The amygdala. Current biology, 10(4), R131.

Diamond, A. (1990). Developmental Time Course in Human Infant Monkeys, and the Neural Bases of, Inhibitory Control in Reaching. Annals of the New York Academy of Sciences, 608, 636-676.

Dollard, J., Doob, L. W., Miller, N. E., Mowrer, O. H., \& Sears, R. R. (1939). Frustration and aggression. New Haven, CT : Yale University Press.

Dumas, J. E. (1989). Treating antisocial behavior in children: Child and family approaches. Clinical Psychology Review, 9, 197-222.

Eisenberg, N., Fabes, R. A., Bernzweig, J., Karbon, M., Poulin, R., \& Hanish, L. (1993). The Relations of Emotionality and Regulation to Preschoolers' Social Skills and Sociometric Status. Child Development, 64, 1418-1438.

Eisenberg, N., \& Spinrad, T. L. (2004). Emotion-related regulation: sharpening the definition. Child development, 75, 334-339.

Eisenberg, N., Spinrad, T. L., Fabes, R. A., Reiser, M., Cumberland, A., Shepard, S. A., Valiente, C., et al. (2004). The relations of effortful control and impulsivity to children's resiliency and adjustment. Child development, 75, 25-46.

Falkenstein, M., Hoormann, J., \& Hohnsbein, J. (1999). ERP components in Go/Nogo tasks and their relation to inhibition. ACTA Psychologica, 101, 267-291.

Fallgatter, A. J., Ehlis, A. C., Seifert, J., Strik, W. K., Scheuerpflug, P., Zillessen, K. E., Herrmann, M. J., et al. (2004). Altered response control and anterior cingulate function in attention-deficit/hyperactivity disorder boys. Clinical Neurophysiology, 115, 973-981.

Farrington, D. P. (1989). Prevention of Delinquent-Behavior. Contemporary Psychology, 34, 694 .

Ferree, T. C., Luu, P., Russell, G. S., \& Tucker, D. M. (2001). Scalp electrode impedance, infection risk, and EEG data quality. Clinical neurophysiology: official journal of the International Federation of Clinical Neurophysiology, 112, 536-44.

Folstein, J. R., \& Van Petten, C. (2008). Influence of cognitive control and mismatch on the N2 component of the ERP: a review. Psychophysiology, 45, 152-170.

Forehand, R. (1986). Parental positive reinforcement with deviant children: Does it make a difference? Child \& Family Behaviour Therapy, 8, 19-25. 
Forgatch, M. S., \& Degarmo, D. S. (1999). Two faces of Janus: Cohesion and conflict. In M. J. Cox Brooks-Gunn,J. (Ed.), Conflict and cohesion in families: Causes and consequences (pp. 167-184). Mahwah, NJ: Erlbaum.

Fox, N. A., \& Calkins, S. D. (2003). The Development of Self-Control of Emotion: Intrinsic and Extrinsic Influences. Motivation and Emotion, 27, 7-26.

Frith, C. D., Friston, K., Liddle, P. F., \& Frackowiak, R. S. (1991). Willed action and the prefrontal cortex in man: a study with PET. Proceedings of the Royal Society: Biological sciences, 244, 241-246.

Gemba, H., Sasaki, K., \& Brooks, V. B. (1986). "Error" potentials in limbic cortex (anterior cingulate area 24) of monkeys during motor learning. Neuroscience letters, 70, 223-227.

Giedd, J. N., Blumenthal, J., Jeffries, N. O., Castellanos, F. X., Liu, H., Zijdenbos, A., Paus, T., et al. (1999). Brain development during childhood and adolescence: A longitudinal MRI study. Nature Neuroscience, 2, 861-863.

Gogtay, N., Giedd, J. N., Lusk, L., Hayashi, K. M., Greenstein, D., Vaituzis, A. C., Nugent III, T. F., et al. (2004). Dynamic mapping of human cortical development during childhood through early adulthood. Proceedings of the National Academy of Sciences of the United States of America, 101, 8174-8179.

Goldin, P. R., McRae, K., Ramel, W., \& Gross, J. J. (2008). The neural bases of emotion regulation: reappraisal and suppression of negative emotion. Biological Psychiatry, 63, 577-86.

Goldstein, L. H., \& Oakley, D. A. (1985). Expected and actual behavioural capacity after diffuse reduction in cerebral cortex: A review and suggestions for rehabilitative techniques with the mentally handicapped and head injured. British Journal of Clinical Psychology, 24, 13-24.

Gratton, G. (1983). A new method for off-line removal of ocular artifact. Electroencephalography and Clinical Neurophysiology, 55, 468-484.

Grave de Peralta Menendez, R., Murray, M. M., Michel, C. M., Martuzzi, R., \& Gonzalez Andino, S. L. (2004). Electrical neuroimaging based on biophysical constraints. Neurolmage, 21, 527-539.

Gross, J. J. (1998). The emerging field of emotion regulation: An integrative review. Review of General Psychology, 2, 271-299. 
Gross, J. J., \& Thompson, R. A. (2007). Emotion regulation: conceptual foundations. In J J Gross (Ed.), Handbook of Emotion Regulation (pp. 3-24). New York: Guilford Press.

Hagemann, T., Levenson, R. W., \& Gross, J. J. (2006). Expressive suppression during an acoustic startle. Psychophysiology, 43, 104-12.

Hajcak, G, McDonald, N., \& Simons, R. F. (2003). To err is autonomic: Error-related brain potentials, ANS activity, and post-error compensatory behavior. Psychophysiology, 40, 895-903.

Hajcak, G, Macnamara, A., \& Olvet, D. M. (2010). Event-Related Potentials, Emotion , and Emotion Regulation: An Event-Related Potentials, Emotion, and Emotion Regulation: An Integrative Review. Developmental Neuropsychology, 35, 129-155.

Hinshaw, S. P. (2007). Moderators and mediators of treatment outcome for youth with ADHD: understanding for whom and how interventions work. Journal of pediatric psychology, 32, 664-75.

Hodges, K. (1999). Child and adolescent functional assessment scale (CAFAS). In M. E. Maruish (Ed.), The use of psychological testing for treatment planning and outcomes assessment (Vol. 2, pp. 631 -664). Mahwah, NJ: Erlbaum.

Hodges, K, \& Gust, J. (1995). Measures of Impairment for Children and Adolescents. Journal of Mental Health Administration, 22, 403-413.

Hodges, K, Wong, M. M., \& Latessa, M. (1998). Use of the child and adolescent functional assessment scale (CAFAS) as an outcome measure in clinical settings. Journal of Behavioral Health Services \& Research, 25, 325-336.

Hodges, Kay, \& Wong, M. M. (1996). Psychometric characteristics of a multidimensional measure to assess impairment: The Child and Adolescent Functional Assessment Scale. Journal of Child and Family Studies, 5, 445-467.

Hoffmann, S., \& Falkenstein, M. (2008). The correction of eye blink artefacts in the EEG: a comparison of two prominent methods. Proceedings of the National Academy of Sciences of the United States of America I, 3, e3004.

Hrynkiw-Augimeri, L., Pepler, D., \& Goldberg, K. (1996). An outreach program for children having police contact. Canada's Mental Health, 41, 7-12.

Johnson, M. H. (2001). Functional brain development in humans. Nature Reviews Neuroscience, 2, 475-483. 
Jones, L. B., Rothbart, M. K., \& Posner, M. I. (2003). Development of executive attention in preschool children. Developmental Science, 6, 498-504.

Jonkman, L M, Lansbergen, M., \& Stauder, J. E. (2003). Developmental differences in behavioral and event-related brain responses associated with response preparation and inhibition in a go/nogo task. Psychophysiology, 40, 752-761.

Jonkman, Lisa M, van Melis, J. J. M., Kemner, C., \& Markus, C. R. (2007). Methylphenidate improves deficient error evaluation in children with ADHD: an event-related brain potential study. Biological psychology, 76, 217-29.

Kappas, A. (2011). Emotion and Regulation are One! Emotion Review, 3, 17-25.

Kappenman, E. S., \& Luck, S. J. (2010). The effects of electrode impedance on data quality and statistical significance in ERP recordings. Psychophysiology, 47, 888904.

Kazdin, A E. (2001). Progression of therapy research and clinical application of treatment require better understanding of the change process. Clinical PsychologyScience and Practice, 8, 143-151.

Kazdin, Alan E. (2007). Mediators and mechanisms of change in psychotherapy research. Annual Review of Clinical Psychology, 3, 1-27.

Kochanska, G., Murray, K. T., \& Harlan, E. T. (2000). Effortful control in early childhood: Continuity and change, antecedents, and implications for social development. Developmental Psychology, 36, 220-232.

Kopp, C. B. (1989). Regulation of Distress and Negative Emotions: A Developmental View. Developmental Psychology, 25, 11.

Ladouceur, C D, Dahl, R. E., Birmaher, B., Axelson, D. A., \& Ryan, N. D. (2006). Increased error-related negativity (ERN) in childhood anxiety disorders: ERP and source localization. Journal of Child Psychology and Psychiatry, 47, 1073-1082.

Ladouceur, Cecile D, Conway, A., \& Dahl, R. E. (2010). Attentional control moderates relations between negative affect and neural correlates of action monitoring in adolescence. Developmental neuropsychology, 35, 194-211.

Lamm, C., \& Lewis, M. D. (2010). Developmental change in the neurophysiological correlates of self-regulation in high- and low-emotion conditions. Developmental Neuropsychology, 35, 156-176. 
Lamm, C., Zelazo, P. D., \& Lewis, M. D. (2006). Neural correlates of cognitive control in childhood and adolescence: disentangling the contributions of age and executive function. Neuropsychologia, 44, 2139-2148.

Lewis, M D, Granic, I., \& Lamm, C. (2006). Behavioral differences in aggressive children linked with neural mechanisms of emotion regulation 23. Annals of the New York Academy of Sciences, 1094, 164-177

Lewis, M., Granic, I., Lamm, C., Zelazo, P. D., Stieben, J., Todd, R. M., Moadab, I., et al. (2008). Changes in the neural bases of emotion regulation associated with clinical improvement in children with behavior problems. Development and Psychopathology, 20, 913-939.

Lewis, M., \& Todd, R. (2007). The self-regulating brain: Cortical-subcortical feedback and the development of intelligent action. Cognitive Development, 22, 406-430.

Lewis, M., Lamm, C., Segalowitz, S. J., Stieben, J., \& Zelazo, P. D. (2006). Neurophysiological correlates of emotion regulation in children and adolescents. Journal of Cognitive Neuroscience, 18, 430-443.

Lins, O. G., Picton, T. W., Berg, P., \& Scherg, M. (1993). Ocular artifacts in EEG and event-related potentials. I: Scalp topography. Brain topography, 6, 51-63.

Loeber, R., \& Dishion, T. (1983). Early predictors of male delinquency: a review. Psychological bulletin, 94, 68-99.

Luu, P., Collins, P., \& Tucker, D. M. (2000). Mood, personality, and self-monitoring: Negative affect and emotionality in relation to frontal lobe mechanisms of error monitoring. Journal of Experimental Psychology: General, 129, 43-60.

Martinez, C. R., \& Forgatch, M. S. (2001). Preventing problems with boys' noncompliance: Effects of a parent training intervention for divorcing mothers. Journal of Consulting and Clinical Psychology, 69, 416-428.

Merker, B. (2007). Consciousness without a cerebral cortex: A challenge for neuroscience and medicine. Behavioral and Brain Sciences, 63 -134.

Metcalfe, J., \& Mischel, W. (1999). A hot/cool-system analysis of delay of gratification: Dynamics of willpower. Psychological Review, 106, 3-19.

Michel, C. M., Murray, M. M., Lantz, G., Gonzalez, S., Spinelli, L., \& Grave de Peralta, R. (2004). EEG source imaging. Clinical neurophysiology: official journal of the International Federation of Clinical Neurophysiology, 115, 2195-222. 
Mulert, C., Pogarell, O., Juckel, G., Rujescu, D., Giegling, I., Rupp, D., Mavrogiorgou, P., et al. (2004). The neural basis of the P300 potential. Focus on the time-course of the underlying cortical generators. European Archives of Psychiatry and Clinical Neuroscience, 254, 190-8.

Murphey Bridget, C., Eisenberg, N., Fabes, R. A., Shepard, S. A., \& Guthrie, I. K. (1999). Consistency and change in children's emotionality and regulation: A longitudinal study. Merrill-Palmer Quarterly, 45, 413-444.

Ochsner, K. N., Bunge, S. A, Gross, J. J., \& Gabrieli, J. D. E. (2002). Rethinking feelings: an FMRI study of the cognitive regulation of emotion. Journal of Cognitive Neuroscience, 14(8), 1215-29.

Ochsner, K. N., \& Gross, J. J. (2007). The neural architecture of emotion regulation. Handbook of Emotion Regulation (pp. 87-109). New York: Guilford Press.

Olson, I. R., Plotzker, A., \& Ezzyat, Y. (2007). The Enigmatic temporal pole: a review of findings on social and emotional processing. Brain, 130, 1718-1731.

Olvet, D. M., \& Hajcak, G. (2009). The stability of error-related brain activity with increasing trials. Psychophysiology, 46, 957-961.

Padmala, S., \& Pessoa, L. (2008). Affective learning enhances visual detection and responses in primary visual cortex. The Journal of neuroscience: the official journal of the Society for Neuroscience, 28, 6202-6210.

Panksepp, J. (2004). Affective Neuroscience: The Foundations Of Human And Animal Emotions (Google eBook) (p. 480). Oxford University Press.

Patrick, C. J. (2008). Psychophysiological correlates of aggression and violence: an integrative review. Philosophical Transactions of the Royal Society B: Biological Sciences, 363, 2543-2555.

Patterson, G. R., Dishion, T. J., \& Chamberlain, P. (1993). Outcomes and methodological issues relating to treatment of antisocial children. In T. R. Giles (Ed.), Handbook of effective psychotherapy. New York: Plenum Press.

Patterson, G. R., Reid, J., \& Dishion, T. J. (1992). Antisocial boys. Eugene, OR: Castalia.

Paus, T. (2001). Primate anterior cingulate cortex: Where motor control, drive and cognition interface. Nature Reviews Neuroscience, 2, 417-424.

Pessoa, L. (2008). On the relationship between emotion and cognition. Nature reviews. Neuroscience, 9, 148-158. 
Petrides, M., \& Pandya, D. N. (2001). Comparative cytoarchitectonic analysis of the human and the macaque ventrolateral prefrontal cortex and corticocortical connection patterns in the monkey. European Journal of Neuroscience, 16, 291310.

Pezawas, L., Meyer-Lindenberg, A., Drabant, E. M., Verchinski, B. A., Munoz, K. E., Kolachana, B. S., Egan, M. F., et al. (2005). 5-HTTLPR polymorphism impacts human cingulate-amygdala interactions: a genetic susceptibility mechanism for depression. Nature Neuroscience, 8, 828-834.

Phillips, M. L., Drevets, W. C., Rauch, S. L., \& Lane, R. (2003). Neurobiology of emotion perception II: Implications for major psychiatric disorders. Biological Psychiatry, 54, 515-528.

Phillips, M. L., Ladouceur, C. D., \& Drevets, W. C. (2008). A neural model of voluntary and automatic emotion regulation: implications for understanding the pathophysiology and neurodevelopment of bipolar disorder. Molecular psychiatry, 13, 833-57.

Posner, M. I., \& Rothbart, M. K. (1998). Attention, self-regulation and consciousness. Philosophical Transactions of the Royal Society B: Biological Sciences, 353, 19151927.

Posner, M. I., \& Rothbart, M. K. (2000). Developing mechanisms of self-regulation. Development and Psychopathology, 12, 427-441.

Posner, M. I., \& Rothbart, M. K. (2009). Toward a physical basis of attention and self regulation. Physics of Life Reviews, 6, 103-120.

Pourtois, G., Schwartz, S., Seghier, M. L., Lazeyras, F., \& Vuilleumier, P. (2006). Neural systems for orienting attention to the location of threat signals: an event-related fMRI study. Neurolmage, 31, 920-33.

Ray, R., \& Zald, D. H. (2011). Anatomical insights into the interaction of emotion and cognition in the prefrontal cortex. Neuroscience \& Biobehavioral Reviews, 36, 479501.

Reef, J., Diamantopoulou, S., van Meurs, I., Verhulst, F., \& van der Ende, J. (2010). Predicting adult emotional and behavioral problems from externalizing problem trajectories in a 24-year longitudinal study. European child \& adolescent psychiatry, $19,577-85$.

Ressler, K. J., \& Mayberg, H. S. (2007). Targeting abnormal neural circuits in mood and anxiety disorders: from the laboratory to the clinic. Nature neuroscience, 10, 11161124. 
Robins, L. N., \& Price, R. K. (1991). Adult disorders predicted by childhood conduct problems: Results from the NIMH Epidemiologic Catchment Area project.

Psychiatry: Interpersonal and Biological Processes, 54, 116-132.

Rolls, E. (2004). The functions of the orbitofrontal cortex. Brain and Cognition, 55(1), 11-29.

Rothbart, M. K., Ahadi, S. A., \& Hershey, K. L. (1994). Temperament and social behavior in childhood. Journal of Developmental Psychology, 40, 21-39.

Rubia, K., Overmeyer, S., Taylor, E., Brammer, M., Williams, S. C., Simmons, A., Andrew, C., et al. (2000). Functional frontalisation with age: Mapping neurodevelopmental trajectories with $\mathrm{fMRI}$. Neuroscience and Biobehavioral Reviews, 24, 13-19.

Ruff, H. A., \& Rothbart, M. K. (1996). Attention in early development: Themes and variations. New York: Oxford University Press.

Rypma, B., Berger, J. S., \& D’Esposito, M. (2002). The influence of working-memory demand and subject performance on prefrontal cortical activity. Journal of cognitive neuroscience, 14, 721-31.

Rypma, B., Berger, J. S., Prabhakaran, V., Bly, B. M., Kimberg, D. Y., Biswal, B. B., \& D'Esposito, M. (2006). Neural correlates of cognitive efficiency. Neurolmage, 33, 969-979.

Sabatinelli, D., Bradley, M. M., Fitzsimmons, J. R., \& Lang, P. J. (2005). Parallel amygdala and inferotemporal activation reflect emotional intensity and fear relevance. Neuroimage, 24, 1265-1270.

Schwarz, N., \& Clore, G. L. (1983). Mood, misattribution, and judgments of well-being. Journal of Personality and Social Psychology. American Psychological Association.

Segalowitz, S. J., Santesso, D. L., Murphy, T. I., Homan, D., Chantziantoniou, D. K., \& Khan, S. (2010). Retest reliability of medial frontal negativities during performance monitoring. Psychophysiology, 47, 260-270.

Shackman, A. J., Salomons, T. V., Slagter, H. A., Fox, A. S., Winter, J. J., \& Davidson, R. J. (2011). The integration of negative affect, pain and cognitive control in the cingulate cortex. Nature reviews. Neuroscience, 12, 154-167.

Shaw, P., Kabani, N. J., Lerch, J. P., Eckstrand, K., Lenroot, R., Gogtay, N., Greenstein, D., et al. (2008). Neurodevelopmental trajectories of the human cerebral cortex. The Journal of neuroscience: the Official Journal of the Society for Neuroscience, 28, 3586-3594. 
Smith, J. L., Johnstone, S. J., \& Barry, R. J. (2007). Response priming in the Go/NoGo task: the N2 reflects neither inhibition nor conflict. Clinical neurophysiology: official journal of the International Federation of Clinical Neurophysiology, 118, 343-355.

Smith, J. L., Johnstone, S. J., \& Barry, R. J. (2008). Movement-related potentials in the Go/NoGo task: the P3 reflects both cognitive and motor inhibition. Clinical Neurophysiology, 119, 704-714.

Stieben, J., Lewis, M. D., Granic, I., Zelazo, P. D., Segalowitz, S., \& Pepler, D. (2007). Neurophysiological mechanisms of emotion regulation for subtypes of externalizing children. Development and Psychopathology, 19, 455-480.

Stouthamer-Loeber, M., Loeber, R., \& Thomas, C. (1992). Caretakers seeking help for boys with disruptive and delinquent behavior. Comprehensive Mental Health Care, 2, $158-178$.

Surguladze, S. A., Brammer, M. J., Young, A. W., Andrew, C., Travis, M. J., Williams, S. C. ., \& Phillips, M. L. (2003). A preferential increase in the extrastriate response to signals of danger. Neurolmage, 19, 1317-1328.

Thomas, K. M., Drevets, W. C., Dahl, R. E., Ryan, N. D., Birmaher, B., Eccard, C. H., Axelson, D., et al. (2001). Amygdala response to fearful faces in anxious and depressed children. Archives of General Psychiatry, 58, 1057-1063.

Timmermans, M., van Lier, P. A. C., \& Koot, H. M. (2008). Which forms of child/adolescent externalizing behaviors account for late adolescent risky sexual behavior and substance use? Journal of Child Psychology and Psychiatry, and Allied Disciplines, 49, 386-394.

Tremblay, R E, Masse, B., Perron, D., Leblanc, M., Schwartzman, A. E., \& Ledingham, J. E. (1992). Early disruptive behavior, poor school achievement, delinquent behavior, and delinquent personality: Iongitudinal analyses. Journal of Consulting and Clinical Psychology, 60, 64-72.

Tremblay, R. E., Pihl, R. O., Vitaro, F., \& Dobkin, P. L. (1994). Predicting Early Onset of Male Antisocial Behavior From Preschool Behavior. Archives of General Psychiatry, 51, 732-739.

Troy, A. S., Mauss, I. B., \& Caston, A. T. (in press). Resilience in the face of stress: Emotion regulation as a protective factor. In S. Southwick, D. Charney, M. Friedman, \& B. Litz (Eds.), Resilience to stress. Cambridge University Press.

Tucker, D. M., Derryberry, D., \& Luu, P. (2000). Anatomy and Physiology of Human Emotion: Vertical Integration of Brainstem, Limbic, and Cortical Systems. In J. 
Borod (Ed.), Handbook of the Neuropsychology of Emotion. New York: Oxford University Press.

Vacha-Haase, T., \& Thompson, B. (2004). How to Estimate and Interpret Various Effect Sizes. Journal of Counseling Psychology, 51, 473-481.

Wallstrom, G. L., Kass, R. E., Miller, A., Cohn, J. F., \& Fox, N. a. (2004). Automatic correction of ocular artifacts in the EEG: a comparison of regression-based and component-based methods. International journal of psychophysiology: official journal of the International Organization of Psychophysiology, 53, 105-119.

Woltering, S, Liu, Z., Bazargani, N., \& Lewis, M. D. (2010). Eye blink correction: a test on the preservation of common ERP components. Annual meeting of the Cognitive Neuroscience society. New York.

Woltering, S, \& Lewis, M. D. (2009). Developmental pathway of Emotion Regulation in Childhood: A Neuropsychological Perspective. Mind, brain, and Education, 3, 160169.

Zelazo, P. D., \& Cunningham, W. A. (2007). Executive Funtion - Mechanisms underlying emotion regulation. In J. Gross (Ed.), Handbook of emotion regulation (pp. 135-158). New York: Guilford.

Zelazo, P. D., \& Müller, U. (2002). The balance beam in the balance: reflections on rules, relational complexity, and developmental processes. Journal of Experimental Child Psychology, 81, 458-465.

van Veen, V., \& Carter, C. S. (2002). The anterior cingulate as a conflict monitor: fMRI and ERP studies. Physiology \& Behavior, 77, 477-482. 